ARTICLE

\title{
Dissociable mesolimbic dopamine circuits control responding triggered by alcohol-predictive discrete cues and contexts
}

Milan D. Valyear', Iulia Glovaci ${ }^{1}$, Audrey Zaari ${ }^{1}$, Soraya Lahlou'1, Ivan Trujillo-Pisanty ${ }^{1}$, C. Andrew Chapman ${ }^{1} \&$ Nadia Chaudhri (iD ${ }^{1 凶}$

Context can influence reactions to environmental cues and this elemental process has implications for substance use disorder. Using an animal model, we show that an alcoholassociated context elevates entry into a fluid port triggered by a conditioned stimulus (CS) that predicted alcohol (CS-triggered alcohol-seeking). This effect persists across multiple sessions and, after it diminishes in extinction, the alcohol context retains the capacity to augment reinstatement. Systemically administered eticlopride and chemogenetic inhibition of ventral tegmental area (VTA) dopamine neurons reduce CS-triggered alcohol-seeking. Chemogenetically silencing VTA dopamine terminals in the nucleus accumbens (NAc) core reduces CS-triggered alcohol-seeking, irrespective of context, whereas silencing VTA dopamine terminals in the NAc shell selectively reduces the elevation of CS-triggered alcohol-seeking in an alcohol context. This dissociation reveals new roles for divergent mesolimbic dopamine circuits in the control of responding to a discrete cue for alcohol and in the amplification of this behaviour in an alcohol context.

${ }^{1}$ Center for Studies in Behavioral Neurobiology, Department of Psychology, Concordia University, Montreal, QC, Canada. ${ }^{凶}$ email: nadia.chaudhri@concordia.ca 
T he environmental context in which learning occurs can gate the future expression of that learning ${ }^{1,2}$. Moreover, the influence of context on learning and cognition can be lifechanging for people with substance use disorder ${ }^{3,4}$. In support of this idea, preclinical studies show that contexts associated with drug availability can trigger relapse-like renewal of extinguished drug-seeking behaviour ${ }^{5-7}$. These data bolster a critical role for context in substance use disorders ${ }^{8}$, and extend a central hypothesis in the addiction field, which is that environmental stimuli can prompt drug-seeking, -taking and relapse ${ }^{3,9,10}$. This hypothesis originated in studies on the incentive and motivational properties of discrete drug-predictive cues, which in humans are environmental stimuli that occur in close temporal proximity with drug use (e.g., smell or taste of alcohol). In preclinical studies these stimuli are modelled by pairing drug delivery with a brief, non-drug stimulus (e.g., light and/or tone) ${ }^{11}$. Modern theories on substance use disorder acknowledge that alongside discrete drug cues, drug-associated contexts facilitate problematic substance use $^{12-14}$.

In animal models, a context can be created by introducing a stable configuration of multimodal stimuli to the testing chamber $^{5,13}$. Interestingly, studies on learning and memory processes that use such contexts show that context is a crucial determinant of how animals respond to discrete cues ${ }^{1,15-17}$. This conclusion is germane to people with substance use disorders because discrete drug cues are usually embedded within drug contexts, and the simultaneous occurrence of both discrete drug cues and drug contexts produces stronger drug craving and more rapid initiation of drug use than either one alone ${ }^{18}$.

To understand how discrete drug cues and drug contexts intersect to promote drug-seeking behaviour and to study the neural processes that underpin these interactive effects, we developed an animal model to test how rats respond to a discrete Pavlovian conditioned stimulus (CS) that predicted alcohol in different contexts. We found that CS-triggered approach and entry into a fluid port (i.e., CS-triggered alcohol-seeking) was significantly elevated in an alcohol context, compared to either a novel context or an equally familiar context where alcohol had not previously been consumed ${ }^{19-21}$. Here, we sought deeper insight into the psychological processes underlying elevation of CS-triggered alcohol-seeking by an alcohol context. To determine if this effect was transient or persistent, we examined CS-triggered alcohol-seeking in both an alcohol context and a familiar, neutral context across multiple sessions in the absence of alcohol delivery. After the influence of the alcohol context on CS-triggered alcohol-seeking had subsided, we determined if this context could still impact responding to the CS in a relapse test.

Dopamine is critical for the instantiation ${ }^{22-24}$ and expression ${ }^{25}$ of cue-reward learning, and plays an important role in behaviour motivated by alcohol ${ }^{26}$. The dopamine system is also engaged by context, as context can modulate how ventral tegmental area (VTA) dopamine neurons fire in response to discrete cues ${ }^{27}$. Exposure to alcohol-associated contexts evokes dopamine release in the nucleus accumbens ${ }^{28}(\mathrm{NAc})$, a key nucleus in brain reward circuitry ${ }^{29}$ that is densely innervated by dopaminergic neurons originating in the VTA ${ }^{22,29-31}$. Moreover, the NAc core and shell subregions are hypothesized to have dissociable roles in behaviour motivated by discrete cues and contexts, respectively ${ }^{32-34}$.

This dissociation is supported by instrumental conditioning studies that directly compared NAc core and shell function in the same behavioural task. Functional inactivation ${ }^{35,36}$ or excitotoxic lesion ${ }^{37,38}$ of the NAc core, but not shell, reduced operant responding that was reinforced by discrete cues. Behaviour motivated by context was reduced by functional inactivation ${ }^{39}$ or pharmacological interference of glutamatergic ${ }^{40}$ or dopaminergic $^{41}$ neurotransmission within the NAc shell. Interestingly, the same manipulations in the NAc core also reduced behaviour in these context-dependent tasks ${ }^{39-41}$, which is inconsistent with the aforementioned dissociation. However, this result would be predicted if the task explicitly or inadvertently included a salient, discrete cue (e.g. a lever).

Perhaps the best evidence for this dissociation in NAc function comes from a study showing that antagonism of dopamine D1like receptors in the NAc shell, but not core, reduced contextinduced renewal of heroin-seeking ${ }^{32}$. These results corroborate a role for the NAc shell and its afferent and efferent connections in mediating the impact of context on operant drug-seeking ${ }^{42-45}$. In that same study, the D1-like receptor antagonist in the NAc core, but not shell, reduced responding reinforced by a discrete $\mathrm{cue}^{32}$. Importantly, the cue-induced reinstatement test was conducted in a context that was distinct from the original selfadministration context. This manipulation mitigated the contribution of context to test responding, thereby supporting a role for NAc core dopamine in instrumental responding for a discrete cue.

This compelling body of research is bound by two considerations. First, instrumental responding can be supported by the intrinsically reinforcing properties of non-drug stimuli, such as flashes of light $t^{46,47}$. Studies showing a role for the NAc core in responding for discrete cues do not report if the non-drug stimuli were intrinsically reinforcing, or if they had acquired the capacity to support instrumental responding because of prior association with primary reinforcement during the self-administration phase. Second, in these studies the discrete cue was always presented in a response-contingent manner, whereas when context was used to trigger behaviour it was presented in a response-independent manner. Thus, the dissociation in NAc core versus shell function could be related to the active (response-contingent) versus passive (response-independent) nature of discrete cue and context presentation $^{32}$. Our behavioural task, described briefly above, circumvents these considerations. Rats are trained to associate a brief auditory CS with alcohol in a specific context and acquisition and expression of this CS-alcohol association can be tracked. At test, CS-triggered alcohol-seeking is assessed in an alcohol context and in a neutral context, and both the CS and context are passively presented.

We found previously that CS-triggered alcohol-seeking required functional activity in the NAc core but not shell, whereas context-induced renewal of CS-triggered alcohol-seeking was reduced by functionally inactivating either subregion ${ }^{33}$. Furthermore, functional inactivation of the NAc shell diminished contextual control over CS-triggered alcohol-seeking ${ }^{20}$. In the present study, we used pharmacology and chemogenetics to first determine if the dopamine system was involved in responding to a CS that predicted alcohol when presented in a familiar context where alcohol had not previously been consumed. Next, we used a validated, circuit-specific chemogenetic approach to test two predictions emerging from the hypothesis that the NAc core and shell subregions have dissociable roles in responding to discrete drug cues and drug contexts, respectively. First, we predicted that if dopamine neurotransmission in the NAc core is necessary for responding to discrete drug cues, then silencing dopaminergic inputs from the VTA to the NAc core would reduce CS-triggered alcohol-seeking regardless of where the CS was experienced. Second, if dopamine in the NAc shell is necessary for contextmediated drug-seeking then silencing dopaminergic inputs from the VTA to the NAc shell would selectively reduce the elevation of CS-triggered alcohol-seeking in an alcohol context, without affecting CS-triggered alcohol-seeking in a neutral context. Our results are consistent with these predictions, and reveal that divergent mesolimbic dopamine circuits control responding to discrete cues for alcohol in a context-dependent manner. 


\section{Results}

An alcohol context invigorates CS-triggered alcohol-seeking. Conditioned approach and entry into a fluid port triggered by a discrete CS that predicted alcohol (i.e., CS-triggered alcoholseeking) is significantly elevated in a context associated with prior alcohol intake (alcohol context), relative to a familiar, neutral context where alcohol was never consumed ${ }^{19-21}$. To determine if this effect was transient or persistent, we examined CS-triggered alcohol-seeking in an alcohol context and a neutral context across multiple sessions without alcohol delivery (i.e., extinction). Once the behavioural impact of the alcohol context was extinguished, we determined if the alcohol context retained the ability to influence CS-triggered alcohol-seeking in a priming-induced relapse test.

Outbred, male Long-Evans rats $(n=22)$ were acclimated to drinking 15\% ethanol (alcohol) in their home-cages for 12 sessions (Supplementary Fig. 1a) and then given Pavlovian conditioning sessions in which 15 presentations of a discrete, 10 -s auditory CS were paired with alcohol $(0.2 \mathrm{ml}$ per CS; $3.0 \mathrm{ml}$ per session) delivered into a fluid port for oral intake. Pavlovian conditioning sessions occurred in a distinct, alcohol context created by visual, olfactory and tactile stimuli in the conditioning chamber, and were alternated daily with sessions in a different, neutral context where alcohol was never available (Fig. 1a). While in the neutral context, half of the rats received presentations of an auditory stimulus that was distinct from their CS (referred to as the neutral stimulus, NS group), whereas the remainder did not (no-NS group). The purpose of the NS was to equate the alcohol and neutral contexts in terms of acoustical salience. Since there were no significant main effects or interactions as a function of this condition, data reported herein were collapsed across group, and an NS was included in the design of all subsequent experiments (see Supplementary Tables 1 and 2 for summaries of all experiments).

Rats learned to selectively enter the fluid port during the CS (Supplementary Figs. 2a, 3a and 4a). Following acquisition, we examined CS port-entries in two counterbalanced tests, one in the alcohol context and one in the neutral context. At test, the CS was presented as in prior Pavlovian conditioning sessions, but without alcohol (Fig. 1b).

CS port-entries at test were higher than port-entries made during the PreCS interval, and were significantly elevated in the alcohol context relative to the neutral context $(p=0.001$; Fig. 1c, Supplementary Fig. 5a, d, Supplementary Video 1). There was no impact of context on port-entries made between CS trials (NonCS, Fig. 1d), the latency to initiate a CS port entry (Supplementary Fig. 5b), or the total duration of CS portentries (Supplementary Fig. 5c). Thus, an alcohol context selectively elevated the number of CS port-entries, without affecting other characteristics of the response.

Next, we presented the CS without alcohol in the alcohol and neutral contexts in alternating sessions. Normalized CS port-entries (i.e., CS minus PreCS) decreased across test sessions, but were elevated and maintained at higher levels for longer in the alcohol context (Fig. 1e). We then examined the impact of context on relapse triggered by re-exposure to alcohol. Rats that began extinction in the alcohol context had a relapse test in the neutral context, and vice versa. At test, $0.2 \mathrm{ml}$ of alcohol was delivered into the fluid port $90 \mathrm{~s}$ before the first inter-trial interval and then again during the first of 15 CS trials (Fig. 1f). Normalized CS port-entries increased significantly at test, compared to responding averaged across the last two extinction sessions (one in either context), and was higher in the alcohol context than the neutral context ( $p=$ 0.047; Fig. 1g). Thus, the alcohol context amplified reinstatement in a relapse test conducted after responding in both the alcohol and neutral contexts had diminished to similarly low levels.
Altogether, while CS-triggered alcohol-seeking underwent classical extinction in both the alcohol and neutral contexts, CS port-entries were maintained at a higher level for longer in the alcohol context and were reinstated to a higher level in the alcohol context. These results show the behavioural impact of an alcohol context is persistent.

VTA dopamine neurons support CS-triggered alcohol-seeking. Functional imaging studies implicate dopamine in cue-induced alcohol craving ${ }^{48}$, suggesting that dopamine is involved in responding to discrete alcohol cues experienced outside drug contexts (i.e., laboratory setting). We tested this hypothesis in our animal model. A subset of rats $(n=11)$ from experiment 1 were retrained in the procedure described above and then CS portentries without alcohol were tested in a neutral context following subcutaneous injection of saline or a dopamine D1-like (SCH23390, $10 \mu \mathrm{g}$ per $\mathrm{kg}$ ) or dopamine D2-like (eticlopride, 10 $\mu \mathrm{g}$ per $\mathrm{kg}$ ) receptor antagonist (Fig. 2a). Pretreatment with either antagonist reduced NonCS port-entries, relative to vehicle (Fig. 2b, inset). CS port-entries were also reduced by eticlopride ( $p=0.018)$, but not by SCH23390 ( $p>1$ after correction), relative to vehicle (Fig. 2b). Thus, dopamine neurotransmission at D1-like and D2-like receptors was required for port-directed behaviour, while CS-triggered alcohol-seeking required D2-like, but not D1like receptors. A reduction in NonCS port-entries may have been due to locomotor deficits caused by blocking dopamine receptors; however, the same dose of eticlopride used here did not impact locomotor behaviour in an open field ${ }^{49,50}$. Further, port-entries elicited by a CS that was paired with alcohol were unaffected by $10 \mu \mathrm{g}$ per $\mathrm{kg}$ eticlopride $\mathrm{e}^{51}$.

We then used chemogenetics in $\mathrm{TH}$ ::Cre rats to evaluate the impact of selectively reducing activity in a subset of VTA dopamine neurons on CS-triggered alcohol-seeking in a neutral context. Naïve TH::Cre male rats $(n=12)$ were microinfused bilaterally into the VTA with the double-floxed inhibitory designer receptor construct ${ }^{52}$ AAV8-hSyn-DIO-hM4DimCherry, causing selective expression of the inhibitory designer receptor (hM4Di) in VTA dopamine neurons. This receptor inhibits neuronal firing when bound by the exogenous ligand clozapine- $n$-oxide $(\mathrm{CNO})^{52,53}$. After 12 sessions of home-cage alcohol exposure (Supplementary Fig. 1b) followed by Pavlovian conditioning with context alternation (Supplementary Figs. 2b, 3b and $4 \mathrm{~b}$ ), we tested CS-triggered alcohol-seeking. At test we presented the CS without alcohol in the neutral context $30 \mathrm{~min}$ after intraperitoneal injection of vehicle or CNO $(10 \mathrm{mg}$ per $\mathrm{kg}$ or $20 \mathrm{mg}$ per kg; Fig. $2 \mathrm{a})^{30,53}$. PreCS port-entries were minimal at test, and CS port-entries were reduced in a dose-related manner by $10 \mathrm{mg}$ per $\mathrm{kg}(p=0.03)$ and $20 \mathrm{mg}$ per $\mathrm{kg}(p=0.012) \mathrm{CNO}$ (Fig. 2c). The reduction in CS port-entries was not caused by general decreases in locomotion, as NonCS port-entries were similar across tests (Supplementary Fig. 6a).

To control for potential off-target effects of $\mathrm{CNO}$ or its reverse-metabolite, clozapine, on CS port-entries in a neutral context, a naïve group of $13 \mathrm{TH}:$ :Cre rats received the same surgical, conditioning (Supplementary Fig. 1c, Figs. 2c, 3c and $4 \mathrm{c})$, and test procedures except that they were microinfused with a control virus construct (AAV8-hSyn-DIO-mCherry). Before test, rats received vehicle, the lowest effective dose of CNO (10 mg per $\mathrm{kg}$ ) from our previous experiment, or clozapine at a dose $(0.1 \mathrm{mg}$ per $\mathrm{kg})$ that may result from reverse metabolism of $10 \mathrm{mg}$ per $\mathrm{kg} \mathrm{CNO}^{54}$, using a withinsubject, repeated-measures design. CS port-entries at test in the neutral context were similar following vehicle, $\mathrm{CNO}$, or clozapine (Fig. 2d), as were NonCS port-entries (Supplementary Fig. 6b). In a separate study, CNO (10 mg per kg) had no 
a
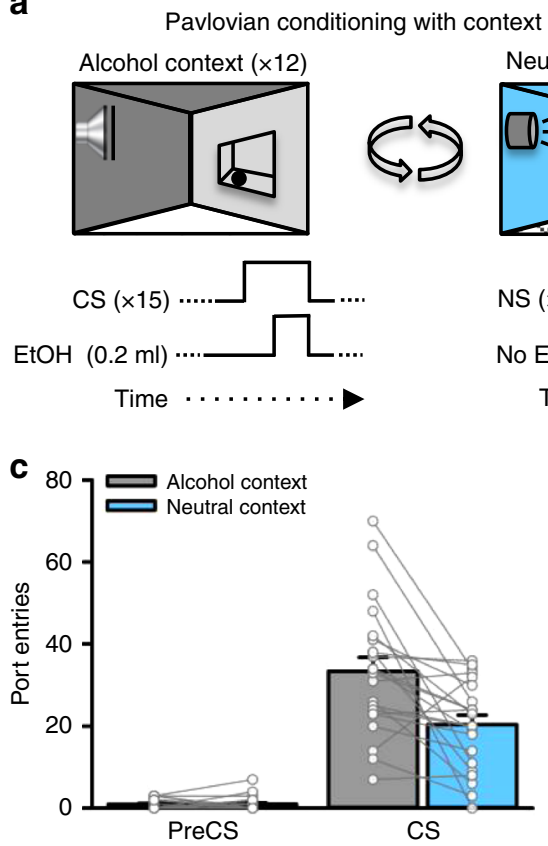

f

Effect of context on relapse

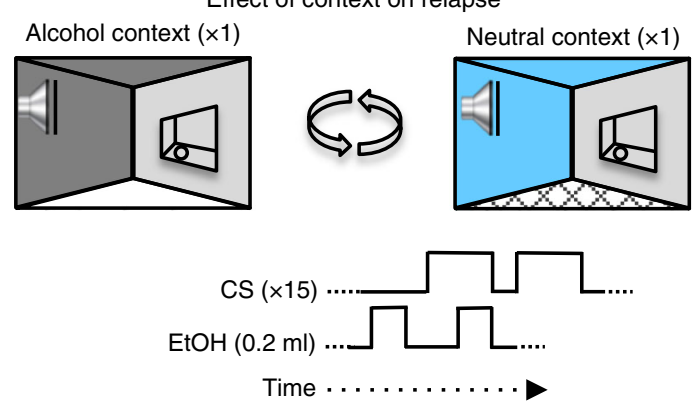

b

Tests for CS-triggered alcohol-seeking
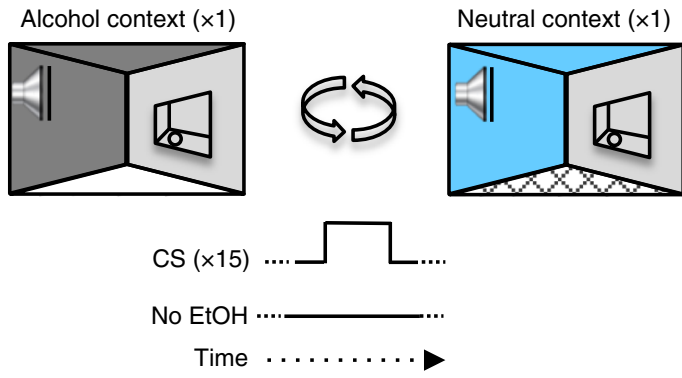

d 140 Alcohol context

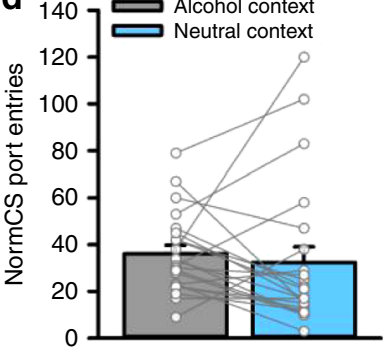

e

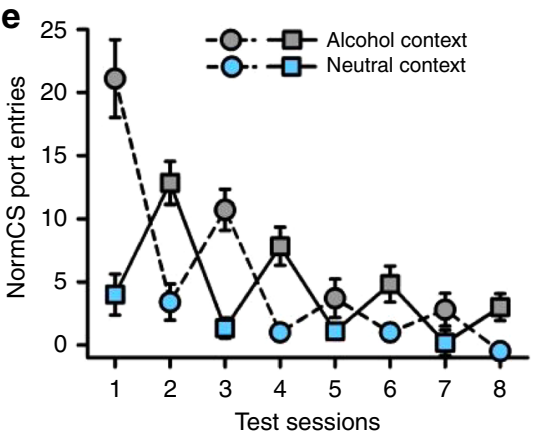

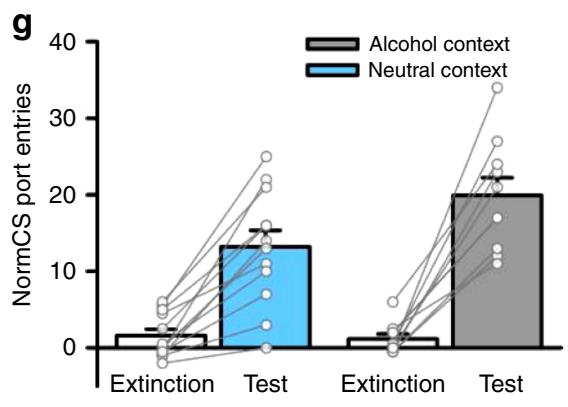

Fig. 1 An alcohol context invigorates CS-triggered alcohol-seeking. a Rats $(n=22)$ received Pavlovian conditioning sessions every other day in a distinct 'alcohol context' where a discrete, conditioned stimulus (CS) was paired with alcohol. On alternating days, rats were exposed to a different, 'neutral context' where a neutral stimulus (NS) was presented without alcohol. b Port-entries elicited by the CS (i.e., CS-triggered alcohol-seeking) were tested in the alcohol and neutral contexts by presenting the CS without alcohol. c At test, CS, but not PreCS, port-entries were elevated in the alcohol context compared to the neutral context [Context $\times$ Interval, $\left.F_{(1,20)}=14.656, p=0.001, \eta_{p}{ }^{2}=0.423 ; t_{(21)}=3.736, p=0.001, \eta_{p}{ }^{2}=0.399\right]$. d NonCS port-entries were unaffected by context [Context, $F_{(1,20)}=0.363, p=0.554, \eta_{p}{ }^{2}=0.018$ ]. e We then conducted four additional tests in the alcohol and neutral contexts to determine if the impact of the alcohol context on CS-triggered alcohol-seeking was persistent. Normalized CS port-entries (CS minus PreCS; mean \pm s.e.m.) decreased across repeated tests [Session, $F_{(3,30)}=18.435, p<0.001, \eta_{p}{ }^{2}=0.648$ ], but were elevated in the alcohol context relative to the neutral context $\left[\right.$ Context, $F_{(1,10)}=30.671, p<0.001, \eta_{p}{ }^{2}=0.754$; Context $\times$ Session, $\left.F_{(3,30)}=5.885, p=0.003, \eta_{p}{ }^{2}=0.370\right]$. Rats received the first test in the alcohol context (dashed line) or neutral context (solid line). $\mathbf{f}$ We then investigated the impact of context on relapse by presenting a drop of alcohol in the fluid port before and during the first CS presentation to reinstate CS port-entries. Half of the rats received the reinstatement test in the neutral context following their last extinction session in the alcohol context and vice versa. $\mathbf{g}$ Relative to an averaged baseline of the last two extinction sessions, normalized CS port-entries were reinstated in both contexts [Phase, $F_{(1,20)}=108.159, p<0.001, \eta_{p}{ }^{2}=0.844$ ], but to a greater extent in the alcohol context than in the neutral context [Phase $\times$ Reinstatement Context, $\left.F_{(1,20)}=6.037, p=0.023, \eta_{p}{ }^{2}=0.232 ; t_{(20)}=2.112, p=0.047, \eta_{p}{ }^{2}=0.182\right]$. Averaged data are mean \pm s.e.m. with data from individual rats overlaid on the bar graphs. Data were analysed using RM ANOVA (c, d, e, g) and Bonferroni-corrected $t$ tests $(\mathbf{c}, \mathbf{g})$. All statistical tests were two-sided. Raw data are available as a supplementary source data file.

impact on responding to a CS that predicted sucrose in a neutral context (Supplementary Fig. 7). Thus, suppression of CS-triggered alcohol-seeking produced by chemogenetically inhibiting VTA dopamine neurons could not be accounted for by non-specific effects of systemically injected $\mathrm{CNO}$ or its reverse metabolism to clozapine and did not generalize to a sucrose reinforcer. These results support the hypothesis that VTA dopamine neuron activity is necessary for alcohol-seeking triggered by a discrete cue in a neutral context.
Dopamine circuits support CS-triggered alcohol-seeking. We used circuit-specific chemogenetics to test the predictions that dopaminergic VTA-to-NAc core projections underpin CStriggered alcohol-seeking regardless of where that CS is experienced, whereas dopaminergic VTA-to-NAc shell inputs are necessary only for the elevation in CS-triggered alcohol-seeking in an alcohol context.

To target VTA dopaminergic projections, we microinfused the AAV8-hSyn-DIO-hM4Di-mCherry construct into the VTA of 


\section{a}

The necessity of dopamine and VTA dopamine neurons for CS-triggered alcohol-seeking
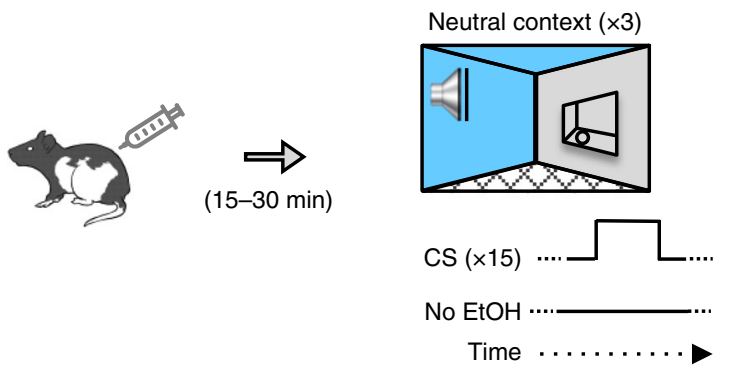

C

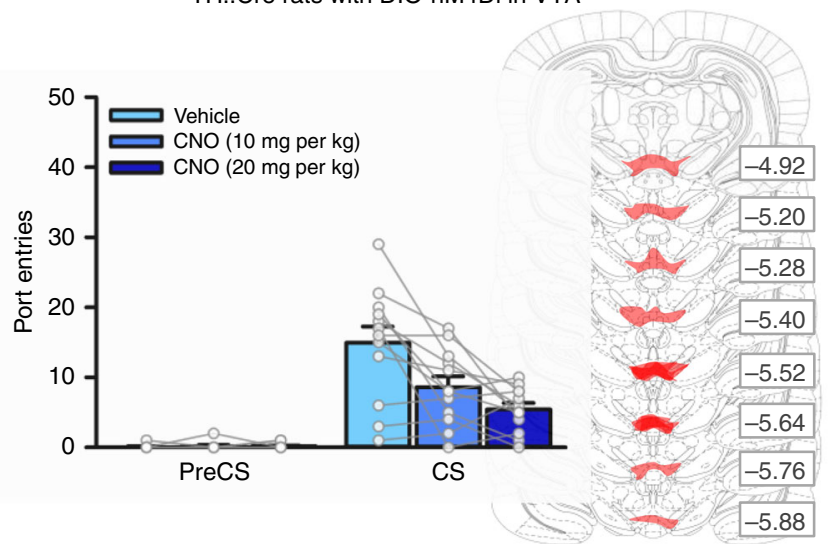

b

Wild-type rats given systemic DA antagonists

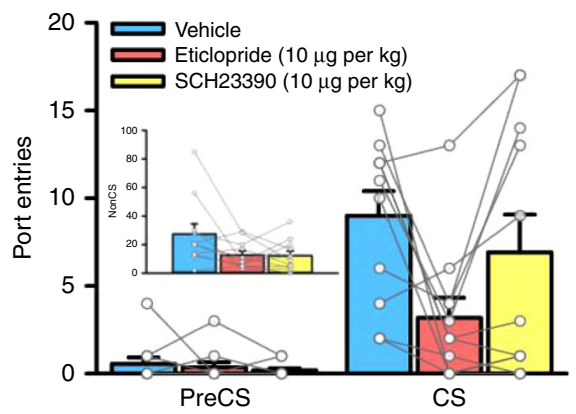

d

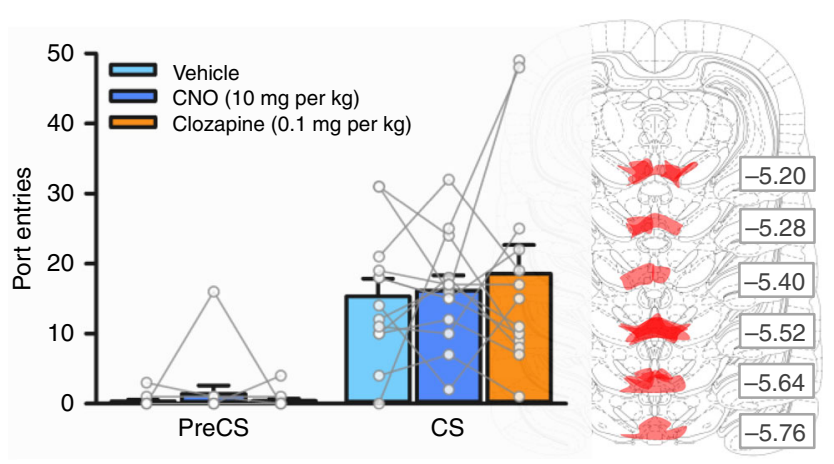

Fig. 2 VTA dopamine neurons are necessary for CS-triggered alcohol-seeking. a We examined the impact of inhibiting dopamine receptors, or inhibiting VTA dopamine neurons, on CS-triggered alcohol-seeking at test in the neutral context. $\mathbf{b}$ In a subset $(n=11)$ of wild-type rats from Fig. 1, systemic administration of the dopamine D2-like receptor antagonist eticlopride [Interval $\times$ Dopamine Antagonist, $F_{(2,20)}=4.294, p=0.028, \eta_{p}{ }^{2}=0.300$; Bonferroni-corrected $\left.t_{(10)}=3.56, p=0.018, \eta_{p}{ }^{2}=.544\right]$, but not the dopamine D1-like receptor antagonist SCH23390 ( $p>1$ after correction), significantly reduced CS port-entries relative to vehicle. NonCS port-entries were also significantly reduced following dopamine receptor antagonist administration relative to vehicle [inset; Dopamine Antagonist, $\left.F_{(2,20)}=4.174, p=0.031, \eta_{p}{ }^{2}=0.294\right]$. c Next, we used a chemogenetic approach in TH::Cre rats $(n=12)$ that expressed the inhibitory designer receptor, hM4Di, in ventral tegmental area (VTA) dopamine neurons. At test, CS port-entries were significantly reduced compared to vehicle [Interval $\times$ CNO Dose, $F_{(2,22)}=10.842, p=0.001, \eta_{p}{ }^{2}=0.596$ ] following systemic administration of $10 \mathrm{mg}$ per $\mathrm{kg}$ and $20 \mathrm{mg}$ per kg of clozapine-n-oxide (CNO) [Bonferroni-corrected $t_{(11)}=3.171, p=0.03, \eta_{p}^{2}=0.478$ for $10 \mathrm{mg}$ per $\mathrm{kg}$, and $t_{(11)}=3.644, p=0.012, \eta_{p}{ }^{2}=0.547$ for $20 \mathrm{mg}$ per kg, relative to vehicle]. Maximal hSyn-DIO-hM4Di-mCherry expression in the VTA for each rat is shown in schematics from the atlas of Paxinos and Watson (2007) ${ }^{85}$. Numbers represent the anterior-posterior coordinate relative to bregma. $\mathbf{d}$ The impact of the lowest effective dose of CNO, and its parent compound clozapine $(0.1 \mathrm{mg}$ per $\mathrm{kg})$, on CS-triggered alcohol-seeking was assessed in TH::Cre rats $(n=13)$ expressing the control DIO-mCherry construct in the VTA. Relative to vehicle, neither $10 \mathrm{mg}$ per $\mathrm{kg}$ CNO nor $0.1 \mathrm{mg}$ per $\mathrm{kg}$ clozapine significantly affected CS port-entries [Interval $\times$ Treatment, $\left.F_{(2,24)}=0.431, p=0.655, \eta_{p}{ }^{2}=0.035\right]$. Maximal hSyn-DIO-mCherry expression for each rat is shown to the right. Averaged data are mean \pm s.e.m. with data from individual rats overlaid on the bar graphs. Data were analysed using RM ANOVA (b-d) and Bonferroni-corrected $t$ tests (b, c). All statistical tests were two-sided. Raw data are available as a supplementary source data file.

TH::Cre rats and implanted bilateral cannulae above the NAc core or shell. This approach allowed us to selectively silence dopaminergic VTA-to-NAc core or VTA-to-NAc shell projections by microinfusing $\mathrm{CNO}$ into either NAc subregion ${ }^{30,53,55}$. Following home-cage alcohol exposure (Supplementary Fig. 1d, e) and Pavlovian conditioning with context alternation (Supplementary Figs. 2d, e, 3d, e and 4d, e), we tested CS-triggered alcohol-seeking in both the alcohol and neutral context after $\mathrm{CNO}$ or vehicle microinfusions. The $\mathrm{CNO}$ dose that we used (3 $\mathrm{mM} ; 0.3 \mu \mathrm{l}$ per hemisphere) did not influence CS port-entries in either the alcohol or neutral contexts in control rats without designer receptors (Supplementary Fig. 8), and had no nonspecific effects on motivated behaviour ${ }^{56,57}$.

In eight $\mathrm{TH}:$ :Cre rats with cannulae targeting the NAc core (Fig. 3a), CS port-entries were elevated over PreCS port-entries and higher at test in the alcohol context, compared to the neutral context (Fig. 3b). Clozapine- $n$-oxide in the NAc core reduced CS port-entries in both the alcohol and neutral contexts $(p=0.043$; Fig. 3b). NonCS port-entries were unaffected by CNO and showed a trend towards elevation in the alcohol context compared to the neutral context (Supplementary Fig. 6c). A VTA-to-NAc core dopamine circuit was thus necessary for CStriggered alcohol-seeking, irrespective of the context in which the discrete cue was experienced.

In a separate experiment using $11 \mathrm{TH}::$ Cre rats with cannulae targeting the NAc shell (Fig. 4a), CNO had no effect on CS portentries at test in the neutral context $(p=0.721$; Fig. $4 \mathrm{~b})$. However, the same manipulation reduced CS port-entries relative to vehicle $(p=0.011$; Fig. $4 \mathrm{~b})$ in the alcohol context. NonCS port-entries were unaffected by CNO treatment, and were significantly higher in the alcohol context than in the neutral context (Supplementary Fig. 6d). These three findings suggest a VTA-to-NAc shell 
a $\mathrm{TH}:$ :Cre rats with DIO-hM4Di in VTA and microinfusions in the NAc core

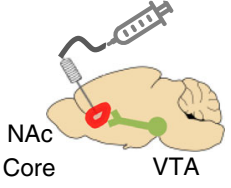

Microinfusion

(Vehicle or $3 \mathrm{mM}$ CNO, $0.3 \mu \mathrm{l}$ per side)

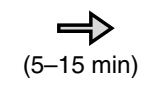

$-15 \mathrm{~min}$ ) b

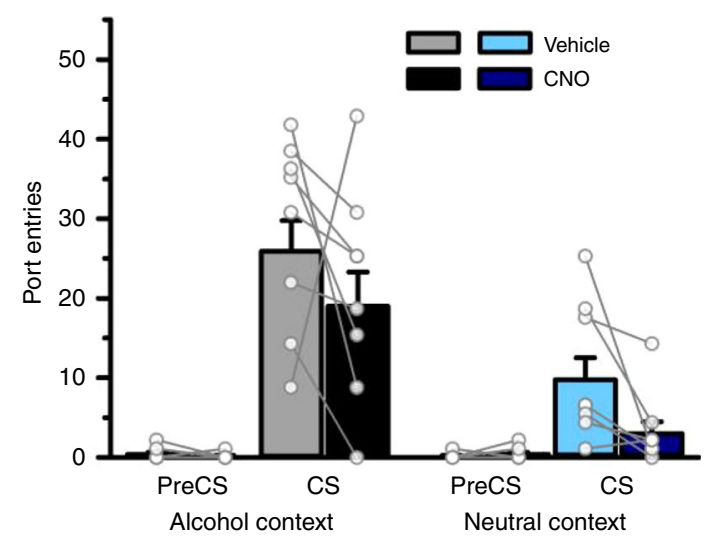

Alcohol context $(\times 2)$
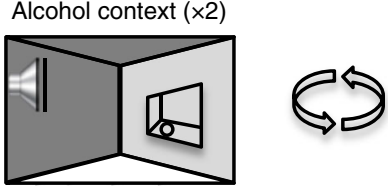

Neutral context $(\times 2)$

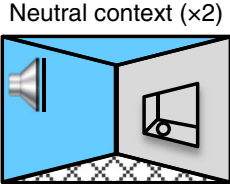

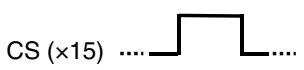

No EtOH

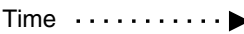

C

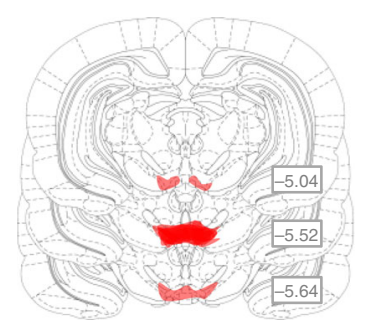

d

Fig. 3 A VTA-to-NAc core dopamine circuit is necessary for CS-triggered alcohol-seeking. a TH::Cre rats expressing the inhibitory designer receptor hM4Di in VTA dopamine neurons received Pavlovian conditioning with context alternation, and then CS-triggered alcohol-seeking was tested four times per rat, twice in the alcohol context and twice in the neutral context. Rats received a microinfusion of vehicle or CNO $(3 \mathrm{mM}, 0.3 \mu \mathrm{l})$ into the NAc core $(n=8)$ prior to each test. $\mathbf{b}$ CS port-entries were elevated at test in the alcohol context relative to the neutral context $\left[\right.$ Context $\times$ Interval, $F_{(1,7)}=44.840, p<0.001$, $\left.\eta_{p}{ }^{2}=0.865\right]$. Relative to vehicle, CS port-entries were significantly reduced following CNO microinfusion in the NAc core in both contexts [Treatment $\times$ Interval, $F_{(1,7)}=5.763, p=0.047, \eta_{p}{ }^{2}=0.452$; Context $\times$ Interval $\times$ Treatment, $\left.F_{(1,7)}=0.002, p=0.962, \eta_{p}{ }^{2}<.001\right]$. Clozapine-n-oxide microinfusion significantly reduced port-entries during the CS interval $(p=0.043)$ but not during the PreCS interval $(p>1$ after correction) as indicated by simple main effects analysis of Treatment collapsed across context. Histological results show mCherry expression in the $\mathbf{c}$ VTA and corresponding injector tip placements in the d NAc core. Averaged data are mean \pm s.e.m. with data from individual rats overlaid on the bar graphs. Data were analysed using RM ANOVA (b) and Bonferroni-corrected simple main effects (b). All statistical tests were two-sided. Raw data are available as a supplementary source data file.

dopamine circuit was not required for alcohol-seeking triggered by a discrete cue per se, but supported the elevation of CStriggered alcohol-seeking in an alcohol context.

NonCS port-entries in this procedure may reflect a direct, excitatory association between context and alcohol, or unconditioned locomotor or exploratory behaviour. The lack of effect of VTA-to-NAc core or VTA-to-NAc shell inhibition on NonCS port-entries suggests that these projections were not necessary for these behavioural effects.

Together, the results from these two experiments reveal that a VTA-to-NAc core dopamine circuit subserves alcohol-seeking triggered by a discrete CS, while a diverging VTA-to-NAc shell dopamine circuit supports the elevation of CS-triggered alcoholseeking in an alcohol context.

Validation of circuit-specific chemogenetic approach. We validated the selectivity of Cre for TH-positive neurons, and the transfection efficiency of the AAV8-hSyn-DIO-hM4Di-mCherry construct in $\mathrm{TH}::$ Cre rats ${ }^{52,58}$. Brains from four $\mathrm{TH}: \mathrm{Cre}^{+/-}$rats that received home-cage alcohol exposure and Pavlovian conditioning with context alternation were immunohistochemically labelled for $\mathrm{TH}$ and an amplified mCherry signal. In a single optical plane through the VTA at approximately bregma -5.5 $\mathrm{mm}$ (Fig. $5 \mathrm{a}, \mathrm{d}$ ), $12.0 \pm 1.5$ cells were mCherry positive, $52.3 \pm 6.3$ were TH positive, and $11.6 \pm 1.5$ were colocalized (Fig. 5b). These counts produced an average selectivity of mCherry expression for TH-positive cells of $95.8 \%$ and a transfection efficiency of $24.8 \%$ (Fig. 5c), which are comparable to published studies $22,30,53,58$. We also observed mCherry-expressing $\mathrm{TH}$-positive processes in the NAc (Supplementary Figs. 9, 10, and 11).

We conducted in vitro intracellular recordings of excitatory synaptic potentials in NAc core medium spiny neurons (MSNs) to validate the ability of CNO to inhibit hM4Di-expressing terminals of VTA dopamine neurons in the region where our in vivo manipulations occurred. The NAc core showed strong mCherry fluorescence in the region of recorded neurons (Supplementary Fig. 11b, e). Cells were identified as MSNs based on characteristic features of depolarization ${ }^{59,60}$ and action potential waveforms (Supplementary Fig. 11c).

$\mathrm{CNO}$ reduced the amplitude of excitatory postsynaptic currents (EPSCs) to $65.7 \pm 7.3 \%$ of baseline levels $(p=0.01$; 
a

TH::Cre rats with DIO-hM4Di in VTA and microinfusions in the NAc shell

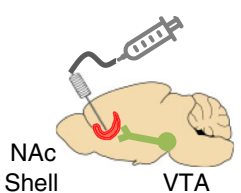

Microinfusion

(Vehicle or $3 \mathrm{mM}$ CNO, $0.3 \mu \mathrm{l}$ per side)

b

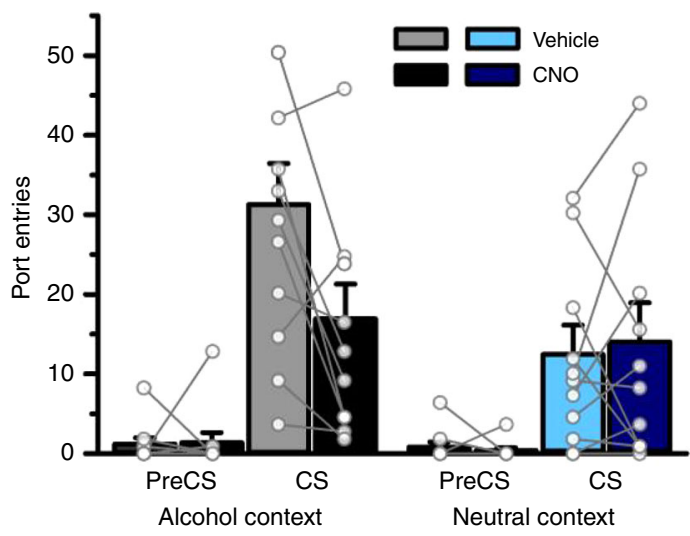

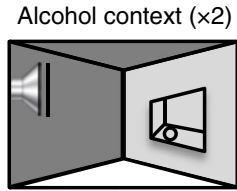
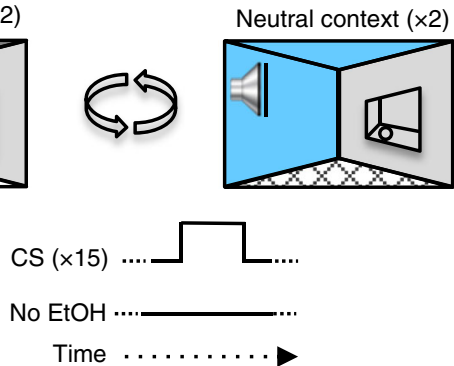

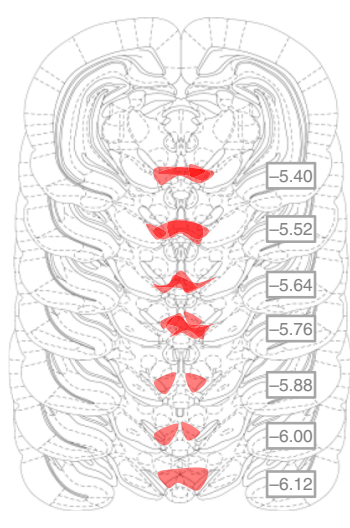

d

Fig. 4 A VTA-to-NAc shell dopamine circuit is necessary for CS-triggered alcohol-seeking in an alcohol context. a TH::Cre rats expressing the inhibitory designer receptor hM4Di in VTA dopamine neurons received Pavlovian conditioning with context alternation, and then CS-triggered alcohol-seeking was tested four times per rat, twice in the alcohol context and twice in the neutral context. Rats received a microinfusion of vehicle or CNO ( $3 \mathrm{mM}, 0.3 \mu \mathrm{l})$ into the NAc shell $(n=11)$ prior to each test. b CS port-entries were elevated at test in the alcohol context relative to the neutral context [Context $\times$ Interval, $\left.F_{(1,10)}=9.562, p=0.011, \eta_{p}{ }^{2}=0.489\right]$. Relative to vehicle, there was no effect of CNO on CS port-entries at test in the neutral context. However, CNO significantly reduced CS port-entries at test in the alcohol context [Context $\times$ Interval $\times$ Treatment, $F_{(1,10)}=5.121, p=0.047, \eta_{p}{ }^{2}=0.339 ; C S$ port-entries in neutral context, $t_{(10)}=-0.367, p=0.721, \eta_{p}{ }^{2}=0.013$; CS Port-entries in alcohol context, $t_{(10)}=3.121, p=0.011, \eta_{p}{ }^{2}=0.493$ ]. Histological results show mCherry expression in the $\mathbf{c}$ VTA and corresponding injector tip placements in the $\mathbf{d}$ NAc shell. Averaged data are mean \pm s.e.m. with data from individual rats overlaid on the bar graphs. Data were analysed using RM ANOVA (b) and Bonferroni-corrected $t$ tests (b). All statistical tests were two-sided. Raw data are available as a supplementary source data file.

Fig. 5e-g). Thus, activation of inhibitory hM4Di designer receptors in terminals of VTA neurons in the NAc core inhibited excitatory postsynaptic MSN responses.

To confirm that the reduction in MSN EPSCs was the result of $\mathrm{CNO}$ actions on designer receptors, we conducted a parallel analysis in NAc core slices that contained VTA dopamine terminals expressing the excitatory designer receptor, hM3Dq. We predicted that $\mathrm{CNO}$, acting on $\mathrm{hM} 3 \mathrm{Dq}$-expressing dopamine terminals in the NAc core, would increase the amplitude of MSN EPSCs, as dopamine has been reported to enhance MSN EPSCs in the NAc ${ }^{61,62}$. Accordingly, CNO significantly increased EPSCs to approximately $137.9 \pm 18.8 \%$ of baseline levels, $\quad(p<0.001$; Fig. $5 \mathrm{~h}-\mathrm{j})$. Thus, activation of excitatory hM3Dq designer receptors upon terminals of VTA neurons in the NAc core increased excitatory postsynaptic MSN responses.

\section{Discussion}

We show that an alcohol context elevated CS-triggered alcoholseeking, and this effect persisted across repeated sessions, and re- emerged after the motivational properties of the alcohol context had been extinguished. Ventral tegmental area dopamine neurons were required for CS-triggered alcohol-seeking in a neutral context, and VTA dopamine input to the NAc core was necessary for CS-triggered alcohol-seeking regardless of where the CS was experienced. Conversely, VTA dopamine input to the NAc shell was not necessary for responding to the discrete CS, but was necessary for the elevation of CS-triggered alcohol-seeking in an alcohol context. This neural dissociation refines our understanding of how the mesolimbic dopamine system regulates behavioural responses to discrete, alcohol-predictive cues in different contexts.

The number of CS port-entries was higher at test in an alcohol context compared to a neutral context; however, there was no impact of context on latency to respond to the CS or the total duration of CS port-entries. These results suggest that a drug context can influence the vigour of conditioned responding to discrete drug cues, but may not impact other features of motivation captured by changes in latency or duration. Interestingly, in a recent study, cigarette smokers 
a
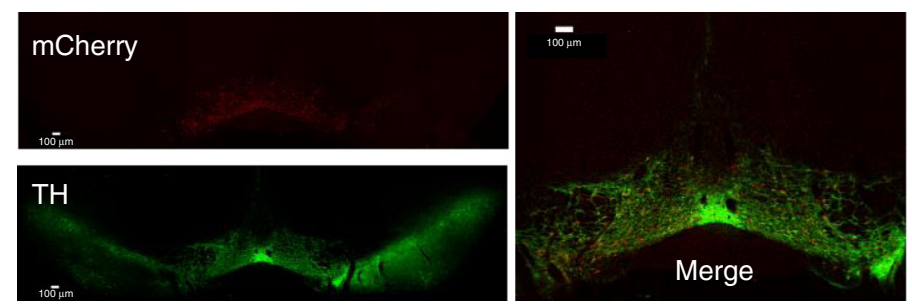

b

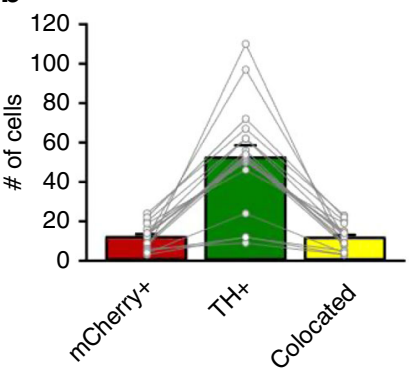

c

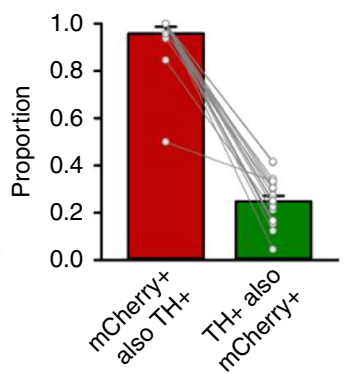

d
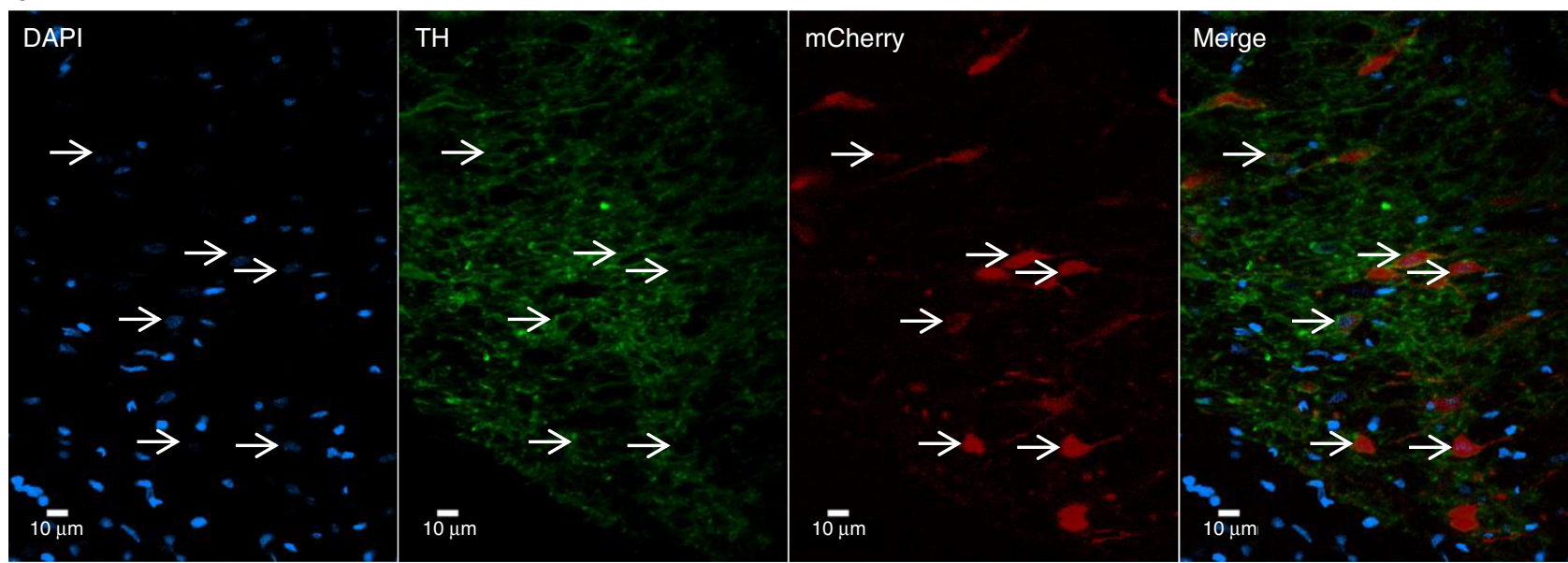

e
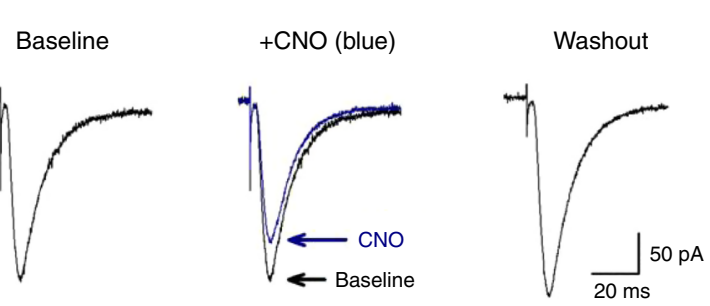

f

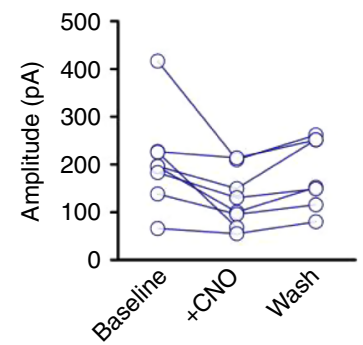

i

h

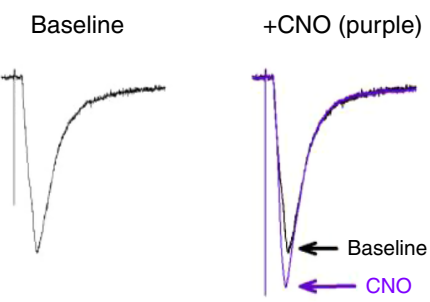

Washout

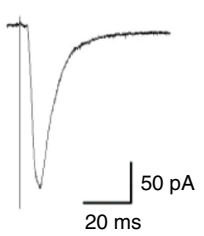

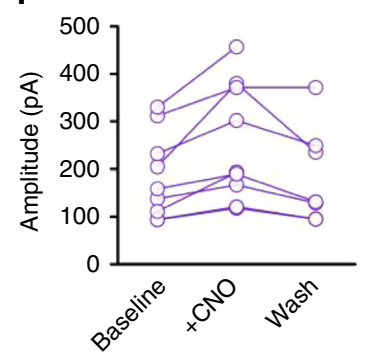
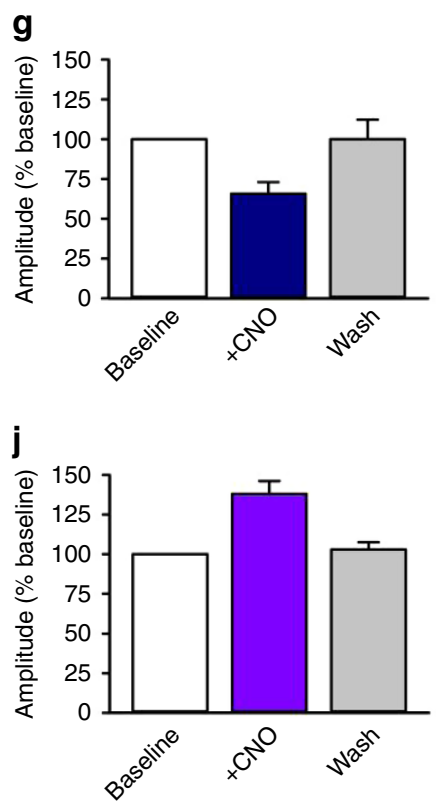

exhibited higher craving after exposure to pictures of discrete smoking cues (e.g., a lit cigarette in an ashtray) that were juxtaposed against projected images of smoking contexts, compared to either cue type alone ${ }^{18}$. Smokers were also faster to light up a cigarette after concurrent exposure to discrete and contextual smoking cues, showing that the combination of these types of environmental signals for cigarette smoking accelerated the onset of smoking behaviour.

We found that an alcohol context persistently influenced CStriggered alcohol-seeking. In the absence of alcohol, CS portentries extinguished in both contexts; however, there was resistance to extinction in the alcohol context, where CS port-entries

remained elevated longer than in the neutral context. Moreover, alternating tests across context produced a saw-tooth pattern of responding, such that CS port-entries increased and then dropped in the alcohol and neutral contexts, respectively. This pattern of responding showcases the remarkable ability of context to control CS-triggered alcohol-seeking. Finally, reinstatement produced by an alcohol prime was significantly higher in the alcohol context than in the neutral context. This effect was unexpected, as rats had stopped discriminating between contexts prior to test. Since the alcohol prime was a different stimulus from the auditory CS, this result suggests that extinguishing one cue across contexts does not prevent a different, non-extinguished cue from 
Fig. 5 Validation of circuit-specific chemogenetic approach. a Representative coronal $\times 4$ optical plane through the VTA showing fluorescence indicative of mCherry (red; top; hM4Di reporter) and TH (green; bottom; Alexa 488), and corresponding merged image (right). b The number of cells ( $n=948$ cells across four rats) counted in each $300 \times 300 \mu \mathrm{m}$ optical section. c Cell counts indicate the specificity of mCherry expression in $\mathrm{TH}+$ neurons and the proportion of $\mathrm{TH}+$ neurons that were transfected ( $n=948$ cells across four rats). d Representative area of a $\times 40$ image used for the analyses in (b) and (c). Cells with colocalized TH and mCherry signals all had a nucleus indicated by DAPI (blue). e Example traces show averaged excitatory post synaptic currents (EPSCs) for an NAc core medium spiny neuron (MSN) before (baseline), during ( + CNO), and after (washout) 5 min application of $1 \mu \mathrm{M}$ CNO to striatal slices containing hm4Di-expressing terminals from VTA dopamine neurons. f Peak amplitudes of EPSCs recorded from individual MSNs innervated by hM4Di-expressing dopaminergic terminals ( $n=8$ cells across five rats). $\mathbf{g}$ Normalized mean EPSC amplitudes for the same group of cells. Clozapine- $n$ oxide reduced EPSC amplitude to $65.7 \pm 7.3 \%$ of baseline $\left[n=8\right.$ cells across five rats; $F_{(2,13)}=6.77, p=0.01 ;$ Newman - Keuls $\left.p=0.01\right]$. Mean EPSC amplitude returned towards baseline values within $20 \mathrm{~min}$ of washout ( $93.9 \pm 8.9 \%$ of baseline). $\mathbf{h}$ Example traces show averaged EPSCs for an MSN before (baseline), during ( $+\mathrm{CNO}$ ), and after (washout) $10 \mathrm{~min}$ application of CNO to striatal slices containing excitatory hM3Dq-expressing terminals from VTA dopamine neurons. i Peak amplitudes of EPSCs recorded from individual MSNs innervated by hm3Dq-expressing terminals ( $n=9$ cells across five rats). $\mathbf{j}$ Normalized mean EPSC amplitudes for the same group of cells. Clozapine- $n$-oxide significantly increased EPSCs to $137.9 \pm 18.8 \%$ of baseline levels, $\left[n=9\right.$ cells across five rats, $F_{(2,14)}=17.84, p<0.001$; Newman-Keuls $\left.p<0.001\right]$. Responses returned to baseline values within 20 min of washout (102.9 $\pm 4.7 \%$ of baseline). Averaged data are mean \pm s.e.m. Data were analysed using RM ANOVA $(\mathbf{g}, \mathbf{j})$ and Newman-Keuls post hoc tests ( $\mathbf{g}, \mathbf{j})$. All statistical tests were two-sided. Raw data are available as a supplementary source data file.

prompting a return of alcohol-seeking behaviour, with this effect amplified in an alcohol context.

When considering translational links between the present data and alcohol use disorder, it should be noted that rats in our study drank low levels of alcohol during the home-cage alcohol exposure phase and Pavlovian conditioning. However, home-cage alcohol intake at levels comparable to those in the present study can alter the motivational underpinnings of instrumental behaviour, rendering goal-directed responding habitual ${ }^{63}$. Also, ingested doses of alcohol within the range of what we report during Pavlovian conditioning result in detectable blood levels of alcohol $^{64}$, suggesting that they produce pharmacological effects. Testing the effect of context on CS-triggered alcohol-seeking in alcohol-dependent rats as well as in female rats are two immediate future directions. Nonetheless, the present finding that CS-triggered alcohol-seeking was persistently elevated in an alcohol context, which we report in male non-dependent rats, is likely relevant for people who drink but have not yet developed problematic drinking behaviour. This view is based on research in college students without an alcohol use disorder, who showed more alcohol-related cognitions and elevated alcohol intake in a bar context compared to a neutral, laboratory environment ${ }^{65}$.

The rat VTA contains a large population of dopamine cell bodies that project to diverse striatal and prefrontal targets ${ }^{22,31,66}$. Ventral tegmental area dopamine cell bodies are organized along a medio-lateral gradient, with relatively medial cells projecting predominantly to medial areas of the striatum, including the NAc shell, and more lateral areas projecting to the NAc core ${ }^{22,29}$. We observed designer receptor expression encompassing the anterior - posterior and medio-lateral expanse of VTA dopamine neurons projecting to both the NAc core and shell, with relatively minimal expression in the substantia nigra. While our transfection was highly selective (95.8\%), only a relatively small proportion of $\mathrm{TH}$ positive neurons (24.8\%) were transfected.

After visualizing mCherry-expressing axons in the NAc, we conducted in vitro electrophysiological experiments to verify that $\mathrm{CNO}$ acting on dopamine terminals expressing designer receptors could control NAc neuronal activity. Clozapine- $n$-oxide either decreased or increased the amplitude of EPSCs onto MSNs dependent upon inhibitory or excitatory designer receptors, respectively. This bidirectional effect corroborates evidence that $\mathrm{CNO}$ acting on designer receptors on dopaminergic inputs to the NAc can modulate evoked dopamine ${ }^{30}$. It is consistent with at least three mechanisms by which dopamine can influence striatal MSN excitability. First, dopamine can act synergistically at D1 and D2 receptors on MSNs to enhance MSN activity ${ }^{67}$. Second, activation of designer receptors may directly modulate evoked
EPSCs by increasing or decreasing co-release of glutamate from VTA dopamine terminals ${ }^{68,69}$. Third, dopamine release from VTA terminals in the NAc can act on corticostriatal terminals to enhance glutamatergic input onto NAc MSNs ${ }^{70,71}$.

Although VTA dopamine neurons are implicated in learning via prediction error ${ }^{23,24}$, no study has directly examined their contribution to CS-triggered alcohol-seeking. We found that blocking dopamine D2-like receptors reduced CS and NonCS port-entries, whereas blocking dopamine D1-like receptors reduced only NonCS port-entries. While systemically administered antagonists can act on multiple, potentially competing dopaminergic circuits, these results implicate the dopamine system in responding to a discrete alcohol CS experienced in a neutral context.

Stronger support for a role of the dopamine system in alcoholseeking driven by discrete cues was provided by the finding that chemogenetically silencing VTA dopamine neurons reduced CStriggered alcohol-seeking in a neutral context. This result corroborates data suggesting a role for cholinergic ${ }^{72}$ and glutamater$\mathrm{gic}^{73}$ signalling within the VTA in cue conditioning with alcohol. Importantly, neither the lowest effective $\mathrm{CNO}$ dose in this experiment nor a dose of clozapine that could have been produced through reverse metabolism of CNO impacted CStriggered alcohol-seeking in rats that did not express designer receptors. Additionally, the lowest $\mathrm{CNO}$ dose that effectively reduced CS-triggered alcohol-seeking had no effect on CStriggered sucrose-seeking. This result may be explained by high redundancy in the neural circuitries that support responding for natural food reinforcers ${ }^{74}$. Our silencing of a modest proportion of VTA dopamine neurons ( 25\%; Fig. 5c) may have been sufficient to disrupt CS-triggered alcohol- but not sucrose-seeking.

Chemogenetically silencing VTA inputs to the NAc core reduced CS-triggered alcohol-seeking, regardless of where the CS was presented, suggesting that this dopaminergic input to the NAc core is critical for responding to discrete cues that predict alcohol. This result is consistent with the finding that noncontingent presentation of a cocaine-predictive discrete cue increased dopamine release in the NAc core, but not shell ${ }^{75}$. The exact nature of the involvement of the VTA-to-NAc core circuit in CS-triggered alcohol-seeking might arise from the NAc core being necessary for orchestrating behaviour in response to the best predictors of reinforcement. Supporting this idea, the development of dopamine transients in the NAc core are time locked to the onset and offset of food-predictive cues ${ }^{76}$, and track closely with the earliest reliable predictor of reinforcement ${ }^{77}$. Remarkably, pairing a cue with optogenetic stimulation of VTA dopamine neurons or their projections to the NAc core, but not 
the NAc shell, leads to the cue acquiring incentive motivational properties $^{22}$. This finding underscores a central role for a VTAto-NAc core dopamine circuit in Pavlovian learning about discrete cues $^{22}$, and supports earlier observations of a role for dopaminergic innervation of the NAc core in Pavlovian conditioned approach behaviour ${ }^{25,76,78}$.

Silencing VTA dopamine inputs to the NAc shell had no effect on CS-triggered alcohol-seeking in a neutral context, but selectively reduced the elevation of this behaviour in an alcohol context. This behavioural dissociation supports the prediction that a VTA-to-NAc shell dopamine circuit is not necessary for responding to the CS per se, but rather mediates the capacity of the alcohol context to elevate CS-triggered alcohol-seeking. This finding supports an emerging hypothesis that the NAc shell is an important hub in neural circuits that mediate the impact of context on drug-seeking behaviour ${ }^{33,35,44,45,79}$. Interestingly, optogenetic inhibition of NAc shell MSNs projecting onto VTA GABAergic interneurons results in a net inhibition of VTA dopamine neurons, and this reduction in dopamine release is associated with attenuation of context-induced renewal of alcohol-seeking in an operant conditioning procedure ${ }^{79}$. We found that chemogenetically silencing dopamine terminals in the NAc core reduced the strength of synaptic inputs onto MSNs. A similar reduction in dopaminergic inputs to the NAc shell may have reduced the excitability of MSNs that project back onto GABAergic interneurons in the VTA ${ }^{79,80}$, contributing to inhibition within the VTA that may regulate the impact of drug contexts on drug-seeking behaviour.

The behavioural dissociation we report between dopaminergic VTA-to-NAc core and VTA-to-NAc shell projections is unlikely to have been caused by $\mathrm{CNO}$ diffusing from one ventral striatal subregion to the next, as we did not detect $\mathrm{CNO}$ in microdialysis samples obtained from the NAc shell after a $0.3-\mu l$ microinfusion of CNO in the NAc core, despite achieving a quantitation limit of $0.3 \mathrm{nM}$ (Supplementary Fig. 12). Additionally, CNO microinfused into the NAc did not impact CS port-entries in rats without designer receptors (Supplementary Fig. 8).

The VTA-to-NAc core and VTA-to-NAc shell experiments were conducted consecutively in separate groups of rats. There was a significant effect of context on NonCS port-entries in the VTA-to-NAc shell but not VTA-to-NAc core experiment and modestly higher levels of CS port-entries at test following vehicle in the VTA-to-NAc shell experiment. To evaluate these potential cohort differences, we calculated a difference score for CS portentries in the alcohol and neutral contexts under vehicle conditions for each experiment. This score accounts for differences in baseline levels of responding across experiments by measuring changes in CS port-entries produced by context irrespective of the magnitude of overall responding. According to this score, CS port-entries were elevated similarly in the alcohol context in the VTA-to-NAc shell $(18.82 \pm 4.89)$ and VTA-to-NAc core (16.13 \pm 4.27) experiments.

In conclusion, we show that context can have a robust and persistent influence on responding to a discrete, alcoholpredictive cue. Distinct mesolimbic dopamine circuits from the VTA-to-NAc core and VTA-to-NAc shell control alcohol-seeking triggered by discrete cues and the amplification of this behaviour by context, respectively. This work elucidates the psychological and neural processes that underlie how animals react to discrete cues in different contexts and has the potential to guide new treatments for substance use disorder.

\section{Methods}

Apparatus. Behavioural training and testing used equipment and software from Med-Associates Inc. (St. Albans, VT, USA). We used 12 conditioning chambers (ENV-009A) with stainless steel floors (ENV-009A-GF), each in a fan-ventilated
( $84-88 \mathrm{~dB})$, sound-attenuating, melamine cubicle $(53.6 \times 68.2 \times 62.8 \mathrm{~cm})$. The right wall featured a fluid port $(17.5 \mathrm{~cm}$ from rear wall, $9 \mathrm{~cm}$ from front door) that contained two wells (ENV-200R3AM). Fluid delivery into one well occurred through a $20 \mathrm{ml}$ syringe attached to a pump (PHM-100, $3.33 \mathrm{rpm}$ ) located outside the cubicle. Fluid port-entries were measured with an infrared beam (ENV-205M) and recorded to a computer using Med PC-IV software, which also controlled fluid delivery and stimulus presentations. The upper left wall featured a clicker stimulus (ENV-135M, $8 \mathrm{~dB}$ above background), a continuous white noise stimulus generator (ENV-225SM, $8 \mathrm{~dB}$ above background), and a white house-light (ENV-215M).

Solutions and reagents. Odours were prepared by adding lemon oil (SAFC Supply Solutions, St-Louis, MO, USA, \#W262528) or benzaldehyde (almond odour, OMEGA Chemical Company Inc., Levis, QC, Canada, \#B37-50) to tap water $(10 \%, \mathrm{v} / \mathrm{v})$. Alcohol (15\% ethanol, v/v) was prepared every week by diluting $95 \%$ ethanol in tap water (room temperature). Eticlopride $\left(\mathrm{C}_{17} \mathrm{H}_{25} \mathrm{ClN}_{2} \mathrm{O}_{3} \cdot \mathrm{HCl}\right.$, Sigma Aldrich, \#E101) and SCH23390 $\left(\mathrm{C}_{17} \mathrm{H}_{18} \mathrm{ClNO} \cdot \mathrm{HCl}\right.$, Sigma Aldrich, \#D054) were dissolved in sterile $0.9 \%$ saline to make separate $10 \mu \mathrm{g}$ per $\mathrm{ml}$ solutions. Clozapine- $n$-oxide (Tocris \#4936 or NIMH C-929) for systemic administration was dissolved in $5 \%$ dimethyl sulfoxide and $95 \%$ sterile $0.9 \%$ saline to make 10 or $20 \mathrm{mg}$ per $\mathrm{ml}$ concentrations. Clozapine (AdooQ, \#A10236-500) was dissolved in 5\% dimethyl sulfoxide and $95 \%$ sterile $0.9 \%$ saline to make a $0.1 \mathrm{mg}$ per ml solution Clozapine- $n$-oxide (Abcam, \#ab141704) was dissolved in sterile $0.9 \%$ saline $(0.3$ $\mathrm{mM}$ for intracerebral microinfusions) or artificial cerebrospinal fluid (ACSF) (1 $\mu \mathrm{M}$ for in vitro electrophysiology). Viral vectors were bought from the University of North Carolina Vector Core [AAV8-hSyn-DIO-hM4D(Gi)-mCherry (titre 5.3 or $\left.4.6 \times 10^{12}\right)$, AAV8-hSyn-DIO-hM3D $(\mathrm{Gq})$-mCherry (titre $\left.5.9 \times 10^{12}\right)$ ] or Addgene [AAV8-hSyn-DIO-hM4D(Gi)-mCherry (titre $2.06 \times 10^{12}$ ), AAV8-hSyn-DIOmCherry (titre $\left.2.1 \times 10^{13}\right)$ ].

Subjects. Twenty-five wild-type male, Long-Evans (220-275 g on arrival, INVIGO), 20 wild-type outbred (4 female, 16 male) Long-Evans (bred in-house) and 94 outbred male, Long-Evans, $\mathrm{TH}: \mathrm{Cre}^{+/-}$rats (bred in-house) were singlehoused in cages with bedding and a nylabone ${ }^{\mathrm{TM}}$ chew toy in a vivarium $\left(21 \pm 2{ }^{\circ} \mathrm{C}\right.$, $40-50 \%$ humidity) maintained on a $12 \mathrm{~h}$ light-dark cycle (lights $\mathrm{ON}$ at $07: 00$, all procedures occurred in the light phase). Rats had unrestricted access to chow (Charles River Rodent Diet, \#5075) and water. Founder TH::Cre rats were generously provided by Dr. Karl Deisseroth ${ }^{58}$. Procedures were approved by the Animal Research Ethics Committee at Concordia University and complied with guidelines from the Canadian Council on Animal Care.

In total, 12 rats failed to acquire Pavlovian conditioning (mean of $<5$ CS portentries per session across last two sessions), 9 had missed cannula placements, 1 had a brain lesion from infection in the target region, 2 experienced a programming error, and 1 had the house-light burn out at test. Data from these rats were excluded.

Surgery. Anesthetized (isoflurane, $5 \%$ induction, $2-3 \%$ maintenance) rats were secured in a stereotaxic frame and administered atropine $(0.1 \mathrm{ml}$ per $\mathrm{kg})$ subcutaneously (s.c.). Bilateral, VTA microinfusions of $1 \mu \mathrm{l}(0.1 \mu \mathrm{l}$ per min, $10 \mathrm{~min}$ diffusion) of AAV8-hSyn-DIO-hM4D(Gi)-mCherry, AAV8-hSyn-DIO-mCherry, or AAV8-hSyn-DIO-hM3D(Gq)-mCherry viral vectors were made through a 26gauge injector connected with PE20 tubing to a Hamilton microinjection syringe on a Harvard Apparatus, Pump 11 Elite. Ventral tegmental area coordinates (in $\mathrm{mm}$ ) from bregma were: AP $-5.5, \mathrm{ML} \pm 1.84$ (with $10^{\circ}$ angle), $\mathrm{DV}-8.33$.

Where appropriate, 26-gauge bilateral guide cannulae (PlasticsOne, C315GSPC) were implanted $3 \mathrm{~mm}$ dorsal to the microinjection site using the following coordinates (in $\mathrm{mm}$ ) at a $10^{\circ}$ angle: NAc core $\mathrm{AP}+1.2, \mathrm{ML} \pm 3.23, \mathrm{DV}-7.11$, and $\mathrm{NAc}$ shell AP $+1.68, \mathrm{ML} \pm 2.23,-7.35$. After surgery, rats received buprenorphine ( $0.1 \mathrm{mg}$ per $\mathrm{kg}$, s.c.) and $\geq 7$ days to recover.

Home-cage alcohol exposure. Rats were acclimated to the taste and pharmacological effects of ethanol ${ }^{51,81}$ across 12,24 -h sessions of access to $15 \%$ ethanol (alcohol) every other day in the home-cage, with water always available. Alcohol was provided in $100 \mathrm{ml}$ graduated cylinders and water in $500 \mathrm{ml}$ bottles. Containers were weighed before and after every 24 -h session, and their positions in the lid of the home-cage were switched in every session. Fluid loss was estimated from control containers placed onto two empty cages. Rats that drank less than $1 \mathrm{~g}$ per $\mathrm{kg}$ of alcohol on session 6 were given two sessions of access to $5 \%$ ethanol and then returned to $15 \%$ ethanol.

Experiment 4 used 10\% sucrose instead of alcohol. Rats were acclimated to $10 \%$ sucrose in the home-cage across two, consecutive 24 -h sessions as described above.

Pavlovian conditioning with context alternation and tests for CS-triggered alcohol-seeking. On the last day of home-cage alcohol exposure, rats were individually handled in the behavioural testing room. On the 2 subsequent days, they were habituated $(20 \mathrm{~min})$ to context 1 and, $24 \mathrm{~h}$ later, to context 2 in the conditioning chambers. Context 1 included black walls, a clear polycarbonate floor, and a lemon odour. Context 2 included clear Plexiglas walls, a wire-mesh floor, and an almond odour. Odours (three sprays) were applied to a petri dish placed in the waste-pan under the chamber floor. 
Rats were assigned to one of the two contexts for Pavlovian conditioning (alcohol context), while the second context served as the neutral context. Discrete stimuli were a 10 -s, continuous white noise or 10 -s clicker $(5 \mathrm{~Hz})$. One stimulus (CS) was paired with alcohol delivery in the alcohol context and the other (neutral stimulus, NS) was presented without alcohol in the neutral context. The purpose of the NS was to equate the acoustical salience of both contexts. Rats were counterbalanced across contexts, stimulus identity, and session order such that there were no differences in home-cage alcohol consumption. Rats then received one training session per day $(73.5 \mathrm{~min})$ that alternated between each context until 12 sessions of Pavlovian conditioning in the alcohol context and 12 sessions of exposure to the NS in the neutral context had occurred.

During training sessions, rats received 15 stimulus presentations (either CS or NS as per the appropriate context) with intervals of 140,260 , or 380 s between trials [mean inter-trial interval (ITI) $=260 \mathrm{~s}$, based on pilot studies]. In the alcohol context, CS presentations co-terminated with $6 \mathrm{~s}$ of syringe pump operation to deliver $0.2 \mathrm{ml}$ of alcohol into the fluid port. After each session in the alcohol context fluid ports were examined to ensure that the alcohol had been consumed and noted as follows: 1 (dry, $0 \mathrm{ml}$ ), 2 (slightly wet, $<0.2 \mathrm{ml}$ ), 3 (wet, $0.2 \mathrm{ml}$ ), 4 (very wet, $>0.2 \mathrm{ml}$ ). In the neutral context, NS presentations also co-terminated with $6 \mathrm{~s}$ of syringe pump operation, but no alcohol was delivered.

The protocol described above was conducted identically in all experiments, with two exceptions. First, in experiment 1, we examined if having an NS present or absent from sessions in the neutral context would impact CS-triggered alcoholseeking at test. There were no differences in acquisition or at test between rats that were trained with or without an NS, so all subsequent experiments included an NS in the neutral context. Second, in experiment $4,10 \%$ sucrose was used instead of alcohol.

At $24 \mathrm{~h}$ after the last training session, we tested responding triggered by the CS alone. In all tests, the CS was presented as during Pavlovian conditioning sessions and syringe pumps were activated, but no alcohol was delivered. The order of the test context and all treatment conditions were counterbalanced in all experiments according to a Latin-square design.

Specific conditions for each experiment included in the main manuscript are described below. Methods for experiments included in the Supplementary material are provided in the corresponding figure captions.

\section{Experiment 1a: Is the impact of context on CS-triggered alcohol-seeking} transient or persistent? Following training as described above, we tested CS portentries in the alcohol context and in the neutral context in male, Long-Evans rats $(n=22)$. Rats then had two re-training sessions, one per day in each context, prior to a second test that occurred in the opposite context.

Starting $24 \mathrm{~h}$ after the second test, we conducted repeated daily test sessions to examine if the elevation of CS port-entries in an alcohol context was transient or persistent. All rats were presented with the CS as during training, without alcohol, in the alcohol and neutral contexts on alternating days for a total of eight sessions (four per context).

After the last repeated test, at which point CS port-entries had extinguished to similar levels in both contexts, we examined the impact of context on CS-triggered alcohol-seeking in a relapse model. All rats received a reinstatement test in the opposite context from the one in which the last of the repeated test sessions had occurred (test in neutral context, $n=12$; test in alcohol context $n=10$ ). At test, a $0.2 \mathrm{ml}$ drop of alcohol was dispensed over $6 \mathrm{~s}$ into the fluid port $30 \mathrm{~s}$ after placement in the chamber. A second $0.2 \mathrm{ml}$ drop of alcohol was delivered during the last $6 \mathrm{~s}$ of the first CS, with no more alcohol delivered for the remainder of the test. This prime served as a reminder of the taste and smell of alcohol.

\section{Experiment 1b: Is dopamine required for CS-triggered alcohol-seeking in a} neutral context? A subset of rats from experiment la $(n=11)$ received three Pavlovian conditioning sessions alternating with three sessions of exposure to the NS in the neutral context. All rats received two $1 \mathrm{ml}$ per $\mathrm{kg}$ s.c. saline habituation injections, $15 \mathrm{~min}$ before each of the last two training sessions, one in each context. Next, three tests were conducted in the neutral context. Tests started $15 \mathrm{~min}$ after systemic (s.c.) administration of vehicle, the dopamine D2-like receptor antagonist eticlopride $(10 \mu \mathrm{g}$ per $\mathrm{kg})$, or the D1-like receptor antagonist SCH23390 (10 $\mu \mathrm{g}$ per $\mathrm{kg})^{26,51}$. Tests were separated by a single Pavlovian conditioning session in the alcohol context and followed a within-subjects design.

\section{Experiment 2: Effect of chemogenetic inhibition of VTA dopamine neurons on} CS-triggered alcohol-seeking in a neutral context. TH::Cre rats expressing $\mathrm{hM} 4 \mathrm{Di}$ in the VTA $(n=12)$ received two $1 \mathrm{ml}$ per kg saline injections (intraperitoneal, i.p.), one in each context, $30 \mathrm{~min}$ before each of the last two training sessions. Next, three tests for CS-triggered alcohol-seeking in the neutral context were conducted after vehicle, $\mathrm{CNO}$ at $10 \mathrm{mg}$ per $\mathrm{kg}$, or $\mathrm{CNO}$ at $20 \mathrm{mg}$ per $\mathrm{kg}$ (i.p.) injection $^{30,53}$. Tests were separated by four retraining sessions, alternating between the alcohol and neutral contexts (two sessions per context).

Experiment 3: Potential off-target effects of CNO and its parent compound clozapine. TH::Cre rats expressing mCherry in the VTA $(n=13)$ received two 1 $\mathrm{ml}$ per $\mathrm{kg}$ saline habituation injections (i.p.), one in each context, $30 \mathrm{~min}$ before each of the last two training sessions. Next, three tests for CS-triggered alcoholseeking in the neutral context were conducted $30 \mathrm{~min}$ after vehicle, $10 \mathrm{mg}$ per $\mathrm{kg}$ $\mathrm{CNO}$ (the lowest effective dose to reduce CS port-entries in experiment 2), or 0.1 $\mathrm{mg}$ per $\mathrm{kg}$ clozapine (a dose that would be produced by the reverse metabolism of $10 \mathrm{mg}$ per $\mathrm{kg} \mathrm{CNO}$ ) (i.p.). Tests were separated by a retraining session in the alcohol context and in the neutral context.

Experiment 4: Effect of chemogenetic inhibition of VTA dopamine neurons on CS-triggered sucrose-seeking in a neutral context. Detailed methods are included in the caption for Supplementary Fig. 7.

Experiment 5: Assessing off-target effects of CNO microinfusion in the nucleus accumbens core and shell. Detailed methods are included in the caption for Supplementary Fig. 8.

Experiment 6: Chemogenetic inhibition of dopaminergic VTA-to-NAc core circuit. TH::Cre rats expressing hM4Di in the VTA $(n=8)$ received a saline habituation microinfusion $(0.15 \mu \mathrm{l}$ over $1 \mathrm{~min})$ into the NAc core $5-15 \mathrm{~min}$ before a training session in the alcohol and neutral contexts. At $24 \mathrm{~h}$ after the last training session, the first of four tests for CS-triggered alcohol-seeking was conducted. A similar number of rats was tested in the alcohol or neutral context after receiving a vehicle or $\mathrm{CNO}(3 \mathrm{mM})^{56,57}$ microinfusion $(0.3 \mu \mathrm{l}$ over $1 \mathrm{~min}) 5-15 \mathrm{~min}$ before the test ${ }^{53,55,56}$. One retraining session in the alcohol context and one in the neutral context separated each of the four tests.

Experiment 7: Chemogenetic inhibition of dopaminergic VTA-to-NAc shell circuit. TH::Cre rats expressing hM4Di in the VTA $(n=11)$ received a saline habituation microinfusion $(0.15 \mu \mathrm{l}$ over $1 \mathrm{~min})$ into the NAc shell before a training session in the alcohol and neutral context. At $24 \mathrm{~h}$ after the last training session, the first of four tests for CS-triggered alcohol-seeking was conducted. A similar number of rats was tested in the alcohol or neutral context after receiving a vehicle or CNO $(3 \mathrm{mM})^{56,57}$ microinfusion $(0.3 \mu \mathrm{l}$ over $1 \mathrm{~min}) 5-15 \mathrm{~min}$ before the test session. One retraining session in the alcohol context and one in the neutral context separated each of the four tests.

Experiment 8: Viral transduction efficiency and selectivity for TH + neurons of hSyn-DIO-hM4Di-mCherry in TH::Cre rats. TH::Cre rats $(n=4)$ were deeply anesthetized with euthanyl ${ }^{\mathrm{TM}}$ (sodium pentabarbitol, $240 \mathrm{mg}$ per $\mathrm{kg}$, i.p.) and perfused with phosphate-buffered saline (PBS, $0.02 \mathrm{M}, \mathrm{pH} 7.2$ ) and $4 \%$ paraformaldehyde in $0.02 \mathrm{M} \mathrm{PBS}(150 \mathrm{ml}, \mathrm{pH} 7.2)$. Brains were immediately removed, cryoprotected in a $4 \%$ paraformaldehyde, $30 \%$ sucrose solution $(50 \mathrm{ml}, 2-3$ days), and then stored at $-80^{\circ} \mathrm{C}$. Brains were sectioned $(40-\mu \mathrm{m}$ thick) using a cryostat $\left(-20^{\circ} \mathrm{C}\right)$ and thaw-mounted onto slides that were stored at $-20^{\circ} \mathrm{C}$.

For immunohistochemistry, slides were removed from the $-20^{\circ} \mathrm{C}$ freezer, covered and allowed to dry, in a fumehood overnight. The entire slide, excluding the label, was then outlined with an ImmEdge ${ }^{\mathrm{TM}}$ hydrophobic barrier pen (Vector Labs, \#H-4000) and then washed twice by pipetting $500 \mu \mathrm{l}$ of $0.01 \mathrm{M}$ PBS onto the slide for $1 \mathrm{~min}$. After the second wash, $500 \mu \mathrm{l}$ of $10 \%$ normal donkey serum (NDS, Sigma Aldrich, \#D9663) in 0.01 M PBS plus $0.3 \%$ Triton X-100 (PBST) was applied to the slide for $30 \mathrm{~min}$. After a $1 \mathrm{~min}$ wash in $0.01 \mathrm{M}$ PBS, $500 \mu \mathrm{l}$ of mouse antimCherry (1:1000, Abcam, \#ab125096) and rabbit anti-TH (1:100, EMD Millipore, \#ab152) in 10\% NDS PBST was applied to the slides and left to incubate for $48 \mathrm{~h}$ at room temperature. Slides were then washed three times with $500 \mu \mathrm{l}$ of $0.01 \mathrm{M}$ PBS for $5 \mathrm{~min}$. Then, $500 \mu \mathrm{l}$ of donkey anti-mouse $\mathrm{IgG}(\mathrm{H}+\mathrm{L})$ alexa $594(1: 200$, Jackson ImmunoResearch labs, \#715-585-150) and donkey anti-rabbit IgG $(\mathrm{H}+\mathrm{L})$ alexa 488 (1:200, Jackson ImmunoResearch Labs, \#711-545-152) in 0.01 M PBS was applied to the slides and left to incubate for $24 \mathrm{~h}$ at room temperature. Slides were left to dry covered at room temperature for $2 \mathrm{~h}$ and then cover-slipped with vectasheild ${ }^{\mathrm{TM}}$ (Vector Labs, \#H-1200) and imaged immediately or stored at $4{ }^{\circ} \mathrm{C}$ until imaging.

To verify that $\mathrm{hM} 4 \mathrm{Di}$ was selectively expressed in $\mathrm{TH}^{+}$cells, six coronal sections spanning $1.2 \mathrm{~mm}$ through the VTA from each of four rats were imaged using a Nikon laser scanning C2 system (Nikon NIS Elements; Fiji v2.0). Sections were surveyed at $\times 4$ magnification using a $594 \mathrm{~nm}$ excitation filter cube epifluorescence to identify the coronal section with the most expansive mCherry fluorescence. This coronal section was then imaged at $\times 4$ magnification with 405 , 488 , and $561 \mathrm{~nm}$ lasers to capture a three-channel (DAPI, mCherry, TH) image of the entire section. Then, $2-4$ images per hemisphere were taken at $\times 40$ magnification to again capture a three-channel image $(\sim 300 \times 300 \mu \mathrm{m})$ for colocalization analyses.

Experiment 9: In vitro intracellular recordings of NAc core medium spiny neurons innervated by VTA dopamine terminals expressing designer receptors. Male, TH::Cre rats $(n=10)$ received stereotaxic surgery to deliver VTA microinfusions of $1 \mu$ l of AAV8-hSyn-DIO-hM4D(Gi)-mCherry $(n=5)$ or AAV8hSyn-DIO-hM3D(Gq)-mCherry $(n=5)$. At $4-6$ weeks later, rats were anaesthetized with isoflurane and decapitated. Brains were rapidly extracted and submerged in an ice-cold HEPES-based ACSF solution containing (in $\mathrm{mM}$ ): $92 \mathrm{NaCl}$, 
$2.5 \mathrm{KCl}, 1.2 \mathrm{NaH}_{2} \mathrm{PO}_{4}, 20$ HEPES, $30 \mathrm{NaHCO}_{3}, 25$ glucose, 5 sodium ascorbate, 2 thiourea, 3 sodium pyruvate, $12 \mathrm{~N}$-acetyl-L-cysteine (NAC), $10 \mathrm{MgSO}_{4}$, and 0.5 $\mathrm{CaCl}_{2}$ ( $\mathrm{pH}$ adjusted to $\approx 7.3-7.4$ using $10 \mathrm{M} \mathrm{NaOH}$ ) saturated with $95 \% \mathrm{O}_{2}$ per $5 \%$ $\mathrm{CO}_{2}$. Coronal slices $(300 \mu \mathrm{m})$ containing the NAc were obtained using a vibratome (Leica, VT1200) and transferred to a warm $\left(34^{\circ} \mathrm{C}\right)$, high-choline incubation solution containing (in mM): 92 choline chloride, $2.5 \mathrm{KCl}, 1.2 \mathrm{NaH}_{2} \mathrm{PO}_{4}, 30$ $\mathrm{NaHCO}_{3}, 20$ HEPES, 25 glucose, 5 sodium ascorbate, 2 thiourea, 3 sodium pyruvate, $12 \mathrm{NAC}, 10 \mathrm{MgSO}_{4}$, and $0.5 \mathrm{CaCl}_{2}$, where they recovered for $12 \mathrm{~min}$. Subsequently, slices were incubated at room temperature, in a normal ACSF solution containing (in mM): $124 \mathrm{NaCl}, 5 \mathrm{KCl}, 1.25 \mathrm{NaH}_{2} \mathrm{PO}_{4}, 2 \mathrm{MgSO}_{4}, 26$ $\mathrm{NaHCO}_{3}, 2 \mathrm{CaCl}_{2}$, and 10 dextrose and were allowed to recover for a minimum of $1 \mathrm{~h}$ prior to experiments. Once transferred into the recording chamber, slices were perfused with normal ACSF at $2 \mathrm{ml}$ per min and were visualized using an upright fluorescence microscope with a $\times 40$ water-immersion objective, differential interference contrast optics (Olympus, BX51WI), and XM-10 monochrome camera for viewing (Olympus, CellSens v1.8). mCherry fluorescence in the NAc core was verified at $\times 4$ and $\times 40$ magnification prior to recordings (see Supplementary Fig. 11).

Whole-cell patch-clamp pipettes made from borosilicate glass (1.0 $\mathrm{mm} \mathrm{OD}, 3$ $-5 \mathrm{M} \Omega$ ) were filled with a recording solution containing (in $\mathrm{mM}$ ): $140 \mathrm{~K}$ gluconate, $5 \mathrm{NaCl}, 2 \mathrm{MgCl}_{2}, 10$ HEPES, 0.5 EGTA, 2 ATP-tris, $0.4 \mathrm{GTP}$-tris ( $\mathrm{pH}$ adjusted to 7.25 using $\mathrm{KOH}, 270-280 \mathrm{mOsm}$ ) and were lowered onto visually identified neurons in the NAc core. Tight seals were obtained (1.3-6.6 G $\Omega$ ), and cells were allowed to stabilize in whole-cell configuration for $10 \mathrm{~min}$ prior to recordings. Recordings were obtained using a Multiclamp $700 \mathrm{~B}$ amplifier (Molecular Devices), digitized (Digidata 1440A, Molecular Devices), and were stored using pClamp 10.3 software (Molecular Devices). Access resistance was 19.9 $\pm 2.2 \mathrm{M} \Omega$, and series resistance was uncompensated. All cells recorded had a resting membrane potential below $-65 \mathrm{mV}$. Cellular input resistance, membrane capacitance, and access resistance were monitored during each recording condition.

Cells were initially selected based on visual criteria; MSNs and GABAergic interneurons possess smaller soma in comparison to cholinergic interneurons $\left(8-20 \mu \mathrm{m}\right.$ vs. $\left.20-50 \mu \mathrm{m}^{59,82}\right)$ and any cells with soma $>30 \mu \mathrm{m}$ were not recorded from. GABAergic interneurons and medium spiny projection (MSN) neurons of the accumbens core were differentiated electrophysiologically by injecting $500 \mathrm{~ms}$ hyperpolarizing and depolarizing current steps between -100 and $100 \mathrm{pA}$ in $10 \mathrm{pA}$ intervals from the holding potential of $-70 \mathrm{mV}$. Peak input resistance was measured at the largest voltage change in response to a $-100 \mathrm{pA}$ pulse, and steadystate input resistance was assessed just prior to the end of the current step. Action potential properties were measured from the first action potential evoked in response to positive current injection.

Synaptic responses were evoked using a bipolar stimulating electrode made from two tungsten electrodes $(\approx 1 \mathrm{M} \Omega$, FHC Inc.) placed approximately $30 \mu \mathrm{m}$ from the recording electrode. Evoked AMPA-receptor-mediated EPCSs were recorded at $-70 \mathrm{mV}$, near the resting membrane potential of MSNs of the NAc core $^{83}$ using constant current stimulation pulses. For each cell, at least ten consecutive synaptic responses free from artifacts or action potentials were averaged for each phase of the recordings. Dopamine release from VTA terminals to the NAc core is under tonic inhibition from aspiny GABAergic interneurons, and dopamine can also modify inhibition in the accumbens ${ }^{83,84}$. Because GABA neurotransmission can alter the excitability of MSNs, we included picrotoxin $(50 \mu \mathrm{M})$ in the ACSF to block $\mathrm{GABA}_{\mathrm{A}}$-mediated inhibition and better assess the effects of CNO on VTA inputs to medium spiny neurons. Recordings were obtained before and after $5 \mathrm{~min}(\mathrm{hM} 4 \mathrm{Di}$ ) or $10 \mathrm{~min}(\mathrm{hM} 3 \mathrm{Dq}$ ) application of $1 \mu \mathrm{M}$ $\mathrm{CNO}$, and were also obtained after $20 \mathrm{~min}$ washout of $\mathrm{CNO}$ in the continued presence of picrotoxin. The amplitudes of averaged synaptic currents were measured using Clampfit 8.2 software (Molecular Devices) and normalized to the amplitude of responses recorded prior to $\mathrm{CNO}$ application.

Experiment 10: Assessing the diffusion of CNO from the NAc core to the NAc shell following microinfusion. Detailed methods are included in the caption for Supplementary Fig. 12.

Histology and imaging. Rats from experiments $2-7$ were deeply anesthetized with euthanyl ${ }^{\mathrm{TM}}$ (sodium pentabarbitol, $240 \mathrm{mg}$ per $\mathrm{kg}$, i. p.) and perfused with PBS $(0.02 \mathrm{M}, 250 \mathrm{ml}, \mathrm{pH} 7.2)$ and $4 \%$ paraformaldehyde in $0.02 \mathrm{M}$ PBS $(150 \mathrm{ml}, \mathrm{pH}$ 7.2). Brains were immediately removed, cryoprotected in a $4 \%$ paraformaldehyde $30 \%$ sucrose solution $\left(50 \mathrm{ml}, \sim 2-3\right.$ days), and then stored at $-80{ }^{\circ} \mathrm{C}$ until they were sectioned $\left(40-\mu \mathrm{m}\right.$ thick) using a cryostat at $-20^{\circ} \mathrm{C}$. Nissl staining was conducted to assess histological placements of injector tips in the NAc core and shell. Unamplified mCherry signal was used to verify successful designer receptor expression by letting slides dry for $24 \mathrm{~h}$ after removal from the $-20^{\circ} \mathrm{C}$ freezer and then coverslipping them with vectasheild ${ }^{\mathrm{TM}}$. We assessed mCherry fluorescence using a Leica DM4000B epifluorescence microscope at $\times 5$ and $\times 10$ magnification.

Analyses and statistics. Statistical analyses were conducted with SigmaPlot ${ }^{\mathrm{TM}}$ v12 or SPSS ${ }^{\mathrm{TM}}$ v20 and graphs were made with SigmaPlot ${ }^{\mathrm{TM}} \mathrm{v} 12$.
Dependent variables: During home-cage alcohol consumption, we measured grams of ethanol consumed per kilograms of body weight ( $\mathrm{g}$ per $\mathrm{kg}$ ). In Pavlovian conditioning and test sessions, we measured the number of: port-entries per session (total port-entries), port-entries during the $10 \mathrm{~s}$ CS (CS port-entries), port-entries made between CS offset and the next CS onset (140,260, or 380 s; NonCS portentries), port-entries in the $10 \mathrm{~s}$ preceding the CS (PreCS port-entries), and CS port-entries minus PreCS port-entries (Normalized CS port-entries).

Data from all experiments were first analysed using repeated-measures (RM) ANOVA with the factor Session and the factors Context (Alcohol, Neutral), Interval (PreCS, CS) and Treatment (Vehicle, CNO), or Treatment (Vehicle, CNO, Clozapine), or CNO Dose (Vehicle, $10 \mathrm{mg}$ per $\mathrm{kg}, 20 \mathrm{mg}$ per $\mathrm{kg}$ ), or Dopamine Antagonist (Vehicle, Eticlopride, SCH23390) as determined by the experiment. A Huynh-Feldt correction was applied when sphericity was violated in these analyses. Significant interactions were decomposed with follow-up two-tailed Bonferroni-corrected $t$ tests or Newman-Keuls post hoc tests. The electrophysiology data met the requirements for normality as indicated by the Kolmogorov-Smirnov test with Lilliefors' correction. All analyses used an alpha level of $p=0.05$.

Reporting summary. Further information on experimental design is available in the Nature Research Reporting Summary linked to this paper.

\section{Data availability}

Raw data for all experiments are available as a supplementary source data file. Source data are provided with this paper.

Received: 7 March 2019; Accepted: 6 July 2020; Published online: 28 July 2020

\section{References}

1. Asratyan, E. A. In Compensatory Adaptations, Reflex Activity, and the Brain (ed. Corson, S. A.) 121-147 (Pergamon Press, 1965).

2. Smith, S. M. Remembering in and out of context. J. Exp. Psychol. Hum. Learn Mem. 5, 460-471 (1979).

3. Ludwig, A. M. Pavlov's 'bells' and alcohol craving. Addict. Behav. 11, 87-91 (1986).

4. Seo, D. \& Sinha, R. In Handbook of Clinical Neurology (eds. Sullivan, E. V. \& Pfefferbaum, A.) vol. 125 (Elsevier B.V., 2014).

5. Crombag, H. S. \& Shaham, Y. Renewal of drug seeking by contextual cues after prolonged extinction in rats. Behav. Neurosci. 116, 169-173 (2002).

6. Chaudhri, N., Sahuque, L. L. \& Janak, P. H. Context-induced relapse of conditioned behavioral responding to ethanol cues in rats. Biol. Psychiatry 64, 203-210 (2008).

7. Hamlin, A. S., Newby, J. \& McNally, G. P. The neural correlates and role of D1 dopamine receptors in renewal of extinguished alcohol-seeking. Neuroscience 146, 525-536 (2007).

8. Siegel, S. \& Ramos, B. M. C. Applying laboratory research: Drug anticipation and the treatment of drug addiction. Exp. Clin. Psychopharmacol. 10, 162-183 (2002).

9. Milton, A. L. \& Everitt, B. J. The persistence of maladaptive memory: Addiction, drug memories and anti-relapse treatments. Neurosci. Biobehav. Rev. 36, 1119-1139 (2012).

10. Stewart, J., de Wit, H. \& Eikelboom, R. Role of unconditioned and conditioned drug effects in the self-administration of opiates and stimulants. Psychol. Rev. 91, 251-268 (1984).

11. Shaham, Y., Shalev, U., Lu, L., de Wit, H. \& Stewart, J. The reinstatement model of drug relapse: history, methodology and major findings. Psychopharmacology 168, 3-20 (2003).

12. Valyear, M. D., Villaruel, F. R. \& Chaudhri, N. Alcohol-seeking and relapse: a focus on incentive salience and contextual conditioning. Behav. Process. 141, 26-32 (2017)

13. Janak, P. H. \& Chaudhri, N. The potent effect of environmental context on relapse to alcohol-seeking after extinction. Open Addict. J. 1, 76-87 (2010).

14. Marchant, N. J., Campbell, E. J., Pelloux, Y., Bossert, J. M. \& Shaham, Y. Context-induced relapse after extinction versus punishment: similarities and differences. Psychopharmacology 236, 439-448 (2019).

15. Rescorla, R. A. \& Wagner, A. R. In Classical Conditioning II: Current Research and Theory (eds. Black, A. H. \& Prokasy, W.), Appleton-Century-Crofts, vol. 21, 64-99 (1972).

16. Valyear, M. D. \& Chaudhri, N. Context controls the timing of responses to an alcohol-predictive conditioned stimulus. Behav. Process. 173, 1-4 (2020).

17. LeCocq, M. R., Randall, P. A., Besheer, J. \& Chaudhri, N. Considering drug associated contexts in substance use disorders and treatment development. Neurotherapeutics 17, 43-54 (2020). 
18. Conklin, C. A. et al. Combined smoking cues enhance reactivity and predict immediate subsequent smoking. Nicotine Tob. Res. 21, 241-248 (2019).

19. Remedios, J., Woods, C., Tardif, C., Janak, P. H. \& Chaudhri, N. Pavlovianconditioned alcohol-seeking behavior in rats is invigorated by the interaction between discrete and contextual alcohol cues: implications for relapse. Brain Behav. 4, 278-289 (2014).

20. Millan, E. Z., Reese, R. M., Grossman, C. D., Chaudhri, N. \& Janak, P. H. Nucleus accumbens and posterior amygdala mediate cue-triggered alcohol seeking and suppress behavior during the omission of alcohol-predictive cues. Neuropsychopharmacology https://doi.org/10.1038/npp.2015.102 (2015).

21. Sciascia, J. M., Reese, R. M., Janak, P. H. \& Chaudhri, N. Alcohol-seeking triggered by discrete Pavlovian cues is invigorated by alcohol contexts and mediated by glutamate signaling in the basolateral amygdala. Neuropsychopharmacology https://doi.org/10.1038/npp.2015.130 (2015).

22. Saunders, B. T., Richard, J. M., Margolis, E. B. \& Janak, P. H. Dopamine neurons create Pavlovian conditioned stimuli with circuit-defined motivational properties. Nat. Neurosci. 21, 1 (2018).

23. Schultz, W., Dayan, P. \& Montague, R. A neural substrate of prediction and reward. Science (80-) 275, 1593-1599 (1997).

24. Steinberg, E. E. et al. A causal link between prediction errors, dopamine neurons and learning. Nat. Neurosci. 16, 966-973 (2013).

25. Di Ciano, P., Little, S. J., Cardinal, R. N., Everitt, B. J. \& Cowell, R. A. Differential involvement of NMDA, AMPA/Kainate, and dopamine receptors in the nucleus accumbens core in the acquisition and performance of Pavlovian approach behavior. J. Neurosci. 21, 9471-9477 (2001).

26. Liu, X. \& Weiss, F. Reversal of ethanol-seeking behavior by D1 and D2 antagonists in an animal model of relapse: differences in antagonist potency in previously ethanol-dependent versus nondependent rats. J. Pharmacol. Exp. Ther. 300, 882-889 (2002).

27. Matsumoto, H., Tian, J. \& Uchida, N. Midbrain dopamine neurons signal aversion in a reward-context-dependent manner. Elife https://doi.org/10.7554/ eLife.17328 (2016).

28. Katner, S. N. \& Weiss, F. Ethanol-associated olfactory stimuli reinstate ethanol-seeking behavior after extinction and modify extracellular dopamine levels in the nucleus accumbens. Alcohol. Clin. Exp. Res. 23, 1751-1760 (1999).

29. Ikemoto, S. Dopamine reward circuitry: two projection systems from the ventral midbrain to the nucleus accumbens-olfactory tubercle complex. Brain Res. Rev. 56, 27-78 (2007)

30. Mahler, S. V. et al. Chemogenetic manipulations of ventral tegmental area dopamine neurons reveal multifaceted roles in cocaine abuse. J. Neurosci. 39, 503-518 (2019).

31. Swanson, L. W. The projections of the ventral tegmental area and adjacent regions: a combined fluorescent retrograde tracer and immunofluorescence study in the rat. Brain Res. Bull. 9, 321-353 (1982).

32. Bossert, J. M., Poles, G. C., Wihbey, K. A., Koya, E. \& Shaham, Y. Differential effects of blockade of dopamine D1-family receptors in nucleus accumbens core or shell on reinstatement of heroin seeking induced by contextual and discrete cues. J. Neurosci. 27, 12655-12663 (2007).

33. Chaudhri, N., Sahuque, L. L., Schairer, W. W. \& Janak, P. H. Separable roles of the nucleus accumbens core and shell in context- and cue-induced alcoholseeking. Neuropsychopharmacology 35, 783-791 (2010).

34. Ito, R., Robbins, T. W., Pennartz, C. M. \& Everitt, B. J. Functional interaction between the hippocampus and nucleus accumbens shell is necessary for the acquisition of appetitive spatial context conditioning. J. Neurosci. 28, 6950-6959 (2008).

35. Fuchs, R. A., Evans, K. A., Parker, M. C. \& See, R. E. Differential involvement of the core and shell subregions of the nucleus accumbens in conditioned cueinduced reinstatement of cocaine seeking in rats. Psychopharmacology 176, 459-465 (2004).

36. Floresco, S. B., McLaughlin, R. J. \& Haluk, D. M. Opposing roles for the nucleus accumbens core and shell in cue-induced reinstatement of foodseeking behavior. Neuroscience 154, 877-884 (2008).

37. Hutcheson, D. M., Parkinson, J. A., Robbins, T. W. \& Everitt, B. J. The effects of nucleus accumbens core and shell lesions on intravenous heroin selfadministration and the acquisition of drug-seeking behaviour under a secondorder schedule of heroin reinforcement. Psychopharmacology 153, 464-472 (2001).

38. Ito, R., Robbins, T. W. \& Everitt, B. J. Differential control over cocaine-seeking behavior by nucleus accumbens core and shell. Nat. Neurosci. 7, 389-397 (2004).

39. Fuchs, R. A., Ramirez, D. R. \& Bell, G. H. Nucleus accumbens shell and core involvement in drug context-induced reinstatement of cocaine seeking in rats. Psychopharmacology 200, 545-556 (2008).

40. Bossert, J. M., Gray, S. M., Lu, L. \& Shaham, Y. Activation of group II metabotropic glutamate receptors in the nucleus accumbens shell attenuates context-induced relapse to heroin seeking. Neuropsychopharmacology 31, $2197-2209$ (2006).
41. Chaudhri, N., Sahuque, L. L. \& Janak, P. H. Ethanol seeking triggered by environmental context is attenuated by blocking dopamine D1 receptors in the nucleus accumbens core and shell in rats. Psychopharmacology 207, 303-314 (2009).

42. Bossert, J. M. et al. Role of projections from ventral subiculum to medial prefrontal cortex to nucleus accumbens shell in context-induced reinstatement of heroin seeking. J. Neurosci. 32, 4982-4991 (2012).

43. Cruz, F. C. et al. Role of nucleus accumbens shell neuronal ensembles in context-induced reinstatement of cocaine-seeking. J. Neurosci. 34, 7437-7446 (2014).

44. Bossert, J. M. et al. Role of projections from ventral subiculum to nucleus accumbens shell in context-induced reinstatement of heroin seeking in rats. Psychopharmacology 233, 1991-2004 (2016).

45. Marchant, N. J. et al. Role of ventral subiculum in context-Induced relapse to alcohol seeking after punishment-imposed abstinence. J. Neurosci. 36, 3281-3294 (2016).

46. Stewart, J. Reinforcing effects of light as a function of intensity and reinforcement schedule. J. Comp. Physiol. Psychol. 53, 187-193 (1960).

47. Caggiula, A. R. et al. Environmental stimuli promote the acquisition of nicotine self-administration in rats. Psychopharmacology 163, 230-237 (2002).

48. Heinz, A. et al. Central processing of alcohol cues and craving correlate with dopamine D2 receptors in ventral striatum. Am. J. Psychiatry 161, 1783-1789 (2004).

49. Khoo, S. Y. -S., Uhrig, A. \& Chaudhri, N. Effects of dopamine receptor antagonism and amphetamine sensitization on sign- and goal-tracking after extended training. BioRxiv https://doi.org/10.1101/848150 (2019).

50. Cook, C. D. \& Beardsley, P. M. The modulatory actions of dopamine D2/3 agonists and antagonists on the locomotor-activating effects of morphine and caffeine in mice. Pharmacol. Biochem. Behav. 75, 363-371 (2003).

51. Sparks, L. M., Sciascia, J. M., Ayorech, Z. \& Chaudhri, N. Vendor differences in alcohol consumption and the contribution of dopamine receptors to Pavlovian-conditioned alcohol-seeking in Long-Evans rats. Psychopharmacology 231, 753-764 (2014).

52. Armbruster, B. N., Li, X., Pausch, M. H., Herlitze, S. \& Roth, B. L. Evolving the lock to fit the key to create a family of $\mathrm{G}$ protein-coupled receptors potently activated by an inert ligand. Proc. Natl. Acad. Sci. USA 104, 5163-5168 (2007).

53. Mahler, S. V. et al. Designer receptors show role for ventral pallidum input to ventral tegmental area in cocaine seeking. Nat. Neurosci. 17, 577-585 (2014).

54. Gomez, J. L. et al. Chemogenetics revealed: DREADD occupancy and activation via converted clozapine. Science (80-) 357, 503-507 (2017).

55. Stachniak, T. J., Ghosh, A. \& Sternson, S. M. Chemogenetic synaptic silencing of neural circuits localizes a hypothalamus $\rightarrow$ midbrain pathway for feeding behavior. Neuron 82, 797-808 (2014)

56. Hsu, T. M. et al. A hippocampus to prefrontal cortex neural pathway inhibits food motivation through glucagon-like peptide-1 signaling. Mol. Psychiatry 23, 1555-1565 (2018).

57. Companion, M. A. \& Thiele, T. E. Assessment of ventral tegmental areaprojecting GABAergic neurons from the bed nucleus of the stria terminalis in modulating binge-like ethanol intake. Eur. J. Neurosci. 48, 3335-3343 (2018).

58. Witten, I. B. et al. Recombinase-driver rat lines: tools, techniques, and optogenetic application to dopamine-mediated reinforcement. Neuron $\mathbf{7 2}$, 721-733 (2011).

59. Chang, H. T. \& Kitai, S. T. Projection neurons of the nucleus accumbens: an intracellular labeling study. Brain Res. 347, 112-116 (1985).

60. Pennartz, C. M. A. \& Kitai, S. T. Hippocampal inputs to identified neurons in an in vitro slice preparation of the rat nucleus accumbens: evidence for feedforward inhibition. J. Neurosci. 17, 2838-2847 (1991).

61. Uchimura, N., Higashi, H. \& Nishi, S. Hyperpolarizing and depolarizing actions of dopamine via D-1 and D-2 receptors on nucleus accumbens neurons. Brain Res. 375, 368-372 (1986).

62. Levine, M. S. et al. Modulatory actions of dopamine on NMDA receptormediated responses are reduced in D1A-deficient mutant mice. J. Neurosci. 16, 5870-5882 (1996)

63. Corbit, L. H., Nie, H. \& Janak, P. H. Habitual alcohol seeking: time course and the contribution of subregions of the dorsal striatum. Biol. Psychiatry 72, 389-395 (2012).

64. LeCocq, M. R., Lahlou, S., Chahine, M., Padillo, L. N. \& Chaudhri, N. Modeling relapse to Pavlovian alcohol-seeking in rats using reinstatement and spontaneous recovery paradigms. Alcohol. Clin. Exp. Res. 42, 1795-1806 (2018).

65. Lau-Barraco, C. \& Dunn, M. E. Environmental context effects on alcohol cognitions and immediate alcohol consumption. Addict. Res. Theory 17, 306-314 (2009).

66. Morales, M. \& Margolis, E. B. Ventral tegmental area: cellular heterogeneity, connectivity and behaviour. Nat. Rev. Neurosci. 18, 73-85 (2017).

67. Hopf, F. W., Cascini, M. G., Gordon, A. S., Diamond, I. \& Bonci, A. Cooperative activation of dopamine D1 and D2 receptors increases spike 
firing of nucleus accumbens neurons via G-protein betagamma subunits. J. Neurosci. 23, 5079-5087 (2003).

68. Stuber, G. D., Hnasko, T. S., Britt, J. P., Edwards, R. H. \& Bonci, A. Dopaminergic terminals in the nucleus accumbens but not the dorsal striatum corelease glutamate. J. Neurosci. 30, 8229-8233 (2010).

69. Yoo, J. H. et al. Ventral tegmental area glutamate neurons co-release GABA and promote positive reinforcement. Nat. Commun. 7, 1-13 (2016).

70. Wang, W. et al. Regulation of prefrontal excitatory neurotransmission by dopamine in the nucleus accumbens core. J. Physiol. 590, 3743-3769 (2012).

71. Hu, X. T. \& White, F. J. Dopamine enhances glutamate-induced excitation of rat striatal neurons by cooperative activation of D1 and D2 class receptors. Neurosci. Lett. 224, 61-65 (1997).

72. Löf, E. et al. Nicotinic acetylcholine receptors in the ventral tegmental area mediate the dopamine activating and reinforcing properties of ethanol cues. Psychopharmacology 195, 333-343 (2007).

73. Pina, M. M. \& Cunningham, C. L. Involvement of ventral tegmental area ionotropic glutamate receptors in the expression of ethanol-induced conditioned place preference. Behav. Brain Res. 313, $23-29$ (2016).

74. Stricker, E. M. \& Zigmond, M. J. In Hunger Basic Mechanisms and Clinical Implications (eds. Norvin, D. et al.) 19-32 (Raven Press Books Ltd., 1976).

75. Ito, R., Dalley, J. W., Howes, S. R., Robbins, T. W. \& Everitt, B. J. Dissociation in conditioned dopamine release in the nucleus accumbens core and shell in response to cocaine cues and during cocaine-seeking behavior in rats. $J$. Neurosci. 20, 7489-7495 (2000).

76. Day, J. J., Roitman, M. F., Wightman, R. M. \& Carelli, R. M. Associative learning mediates dynamic shifts in dopamine signaling in the nucleus accumbens. Nat. Neurosci. 10, 1020-1028 (2007).

77. Saddoris, M. P., Cacciapaglia, F., Wightman, R. M. \& Carelli, R. M. Differential dopamine release dynamics in the nucleus accumbens core and shell reveal complementary signals for error prediction and incentive motivation. J. Neurosci. 35, 11572-11582 (2015).

78. Parkinson, J. A., Willoughby, P. J., Robbins, T. W. \& Everitt, B. J. Disconnection of the anterior cingulate cortex and nucleus accumbens core impairs pavlovian approach behavior: further evidence for limbic corticalventral striatopallidal systems. Behav. Neurosci. 114, 42-63 (2000).

79. Gibson, G. D. et al. Distinct accumbens shell output pathways promote versus prevent relapse to alcohol seeking. Neuron 2, 1-9 (2018).

80. Xia, Y. et al. Nucleus accumbens medium spiny neurons target nondopaminergic neurons in the ventral tegmental area. J. Neurosci. 31, 7811-7816 (2011).

81. Wise, R. A. Voluntary ethanol intake in rats following exposure to ethanol on various schedules. Psychopharmacologia 29, 203-210 (1973).

82. Meredith, G. E. \& Totterdell, S. Microcircuits in nucleus accumbens' shell and core involved in cognition and reward. Psychobiology 27, 165-186 (1999).

83. Pennartz, C. M. A., Dolleman-Van der Weel, M. J. \& Lpoes da Silva, F. H. Differential memebrane porperties and dopamine effects in the shell and core of the rat nucleus accumbens studied in vitro. Neurosci. Lett. 136, 109-112 (1992).

84. Hjelmstad, G. O. Dopamine excites nucleus accumbens neurons through the differential modulation of glutamate and GABA release. J. Neurosci. 24, 8621-8628 (2004).

85. Paxinos, G. \& Watson, C. The Rat Brain in Stereotaxic Coordinates. (Elsevier, 2007).

\section{Acknowledgements}

This work was supported by grants from CIHR (MOP-137030, N.C.), FRQS (Chercheur Boursier Junior 2, N.C.), CFI (John R. Evans Leaders Fund, N.C.) and NSERC (201704802, NC; 2014-0507, C.A.C.). M.D.V. was supported by a Helene Linder Doctoral Fellowship, a Faculty of Arts and Science Graduate Fellowship, and a Concordia Public Scholar Award. We thank Karl Deisseroth and his laboratory for the donation of founder TH::Cre rats, Peter Shizgal for support with establishing the TH::Cre colony, Steve Cabilio for Med-PC programming and data extraction, and Jane Stewart and Shimon Amir for helpful comments on a manuscript draft. CNO content in dialysis samples was analysed by Heng Jiang and Alain Tessier from the Center for Biological Applications of Mass Spectrometry at Concordia University.

\section{Author contributions}

N.C. and M.D.V. designed the behavioural experiments and the microdialysis experiment. N.C., M.D.V., and I.T.-P. designed the microscopy co-localization experiment. C.A.C. and I.G. designed, conducted, and analysed the in vitro electrophysiology experiments. M.D.V analysed all the behavioural and co-localization data. M.D.V., A.Z., and S.L. conducted all behavioural experiments and bred the TH::Cre rats. I.T.-P. assisted with breeding the TH::Cre rats. M.D.V., I.G., C.A.C., and N.C. wrote the manuscript. N.C. obtained funding for this research. All authors reviewed the manuscript and provided comments.

\section{Competing interests}

The authors declare no competing interests.

\section{Additional information}

Supplementary information is available for this paper at https://doi.org/10.1038/s41467 020-17543-4.

Correspondence and requests for materials should be addressed to N.C.

Peer review information Nature Communications thanks Yavin Shaham and the other, anonymous, reviewer(s) for their contribution to the peer review of this work.

Reprints and permission information is available at http://www.nature.com/reprints

Publisher's note Springer Nature remains neutral with regard to jurisdictional claims in published maps and institutional affiliations.

Open Access This article is licensed under a Creative Commons Attribution 4.0 International License, which permits use, sharing, adaptation, distribution and reproduction in any medium or format, as long as you give appropriate credit to the original author(s) and the source, provide a link to the Creative Commons license, and indicate if changes were made. The images or other third party material in this article are included in the article's Creative Commons license, unless indicated otherwise in a credit line to the material. If material is not included in the article's Creative Commons license and your intended use is not permitted by statutory regulation or exceeds the permitted use, you will need to obtain permission directly from the copyright holder. To view a copy of this license, visit http://creativecommons.org/ licenses/by/4.0/

(c) The Author(s) 2020 